\title{
Changes in the interannual SST-forced signals on West African rainfall. AGCM intercomparison
}

\author{
Elsa Mohino • Belén Rodríguez-Fonseca - Teresa Losada - Sébastien Gervois • \\ Serge Janicot $\cdot$ Juergen Bader $\cdot$ Paolo Ruti $\cdot$ Fabrice Chauvin
}

Received: 3 February 2010/Accepted: 5 May 2011/Published online: 18 May 2011

(C) Springer-Verlag 2011

\begin{abstract}
Rainfall over West Africa shows strong interannual variability related to changes in Sea Surface Temperature (SST). Nevertheless, this relationship seem to be non-stationary. A particular turning point is the decade of the 1970s, which witnessed a number of changes in the climatic system, including the climate shift of the late 1970s. The first aim of this study is to explore the change in the interannual
\end{abstract}

Electronic supplementary material The online version of this article (doi:10.1007/s00382-011-1093-2) contains supplementary material, which is available to authorized users.

E. Mohino $(\varangle) \cdot$ S. Gervois

LOCEAN/IPSL, Université Pierre et Marie Curie, Tour 45-55, 4eme étage, 4 place Jussieu, 75252 Paris Cedex 05, France

e-mail: emohino@fis.ucm.es

E. Mohino

Universidad de Sevilla, Sevilla, Spain

B. Rodríguez-Fonseca · T. Losada

Dpto. Geofísica y Meteorología, Universidad Complutense de

Madrid, Madrid, Spain

B. Rodríguez-Fonseca

Instituto de Geociencias (CSIC-UCM), Facultad de CC. Físicas, Plaza de Ciencias 1., 28040 Madrid, Spain

\section{S. Janicot}

LOCEAN/IPSL, IRD, Université Pierre et Marie Curie,

Paris, France

J. Bader

Bjerknes Centre for Climate Research, Bergen, Norway

P. Ruti

Progetto Speciale Clima Globale, Ente Nazionale per le Nuove

Tecnologie, l'Energia e l'Ambiente, Rome, Italy

F. Chauvin

GAME/CNRM, Météo-France/CNRS, Toulouse, France variability of West African rainfall after this shift. The analysis indicates that the dipolar features of the rainfall variability over this region, related to changes in the Atlantic SST, disappear after this period. Also, the Pacific SST variability has a higher correlation with Guinean rainfall in the recent period. The results suggest that the current relationship between the Atlantic and Pacific El Niño phenomena is the principal responsible for these changes. A fundamental goal of climate research is the development of models simulating a realistic current climate. For this reason, the second aim of this work is to test the performance of Atmospheric General Circulation models in simulating rainfall variability over West Africa. The models have been run with observed SSTs for the common period 1957-1998 as part of an intercomparison exercise. The results show that the models are able to reproduce Guinean interannual variability, which is strongly related to SST variability in the Equatorial Atlantic. Nevertheless, problems in the simulation of the Sahelian interannual variability appear: not all models are able to reproduce the observed negative link between rainfall over the Sahel and El Niño-like anomalies in the Pacific, neither the positive correlation between Mediterranean SSTs and Sahelian rainfall.

Keywords Interannual climate variability - West African Monsoon - Atmospheric general circulation models

\section{Introduction}

The decreasing rainfall and devastating droughts in the Sahelian region during the last three decades of the 20th century are among the largest climate changes anywhere (Trenberth et al. 2007). It has been suggested that, at interannual and decadal time scale, the oceanic forcing plays a 
relevant role in determining Sahelian rainfall variability (Folland et al. 1986; Palmer 1986; Rowell et al. 1992; Ward 1998; Camberlin et al. 2001; Giannini et al. 2003; Lu and Delworth 2005; Cook 2008; Caminade and Terray 2010; Mohino et al. 2010; Rodriguez-Fonseca et al. 2010). This is further supported by the fact that the ocean-forced signal of Sahelian rainfall can be isolated in most, if not all, current state-of-the-art models (Paeth and Hense 2004; Giannini et al. 2003; Lu and Delworth 2005; Tippett 2006); these results reinforce those obtained in the early Atmosphere General Circulation Model (AGCM) experiments done with prescribed SSTs (Palmer 1986; Rowell, et al. 1995).

Many works point to two principal summer rainfall variability patterns over West Africa: a dipole pattern, in which anomalies of opposite sign appear north and south of $10^{\circ} \mathrm{N}$; and a monopolar pattern with anomalies of the same sign in the whole region (Motha et al. 1980; Janicot 1992a, b). Although West African precipitation shows strong variability at different time scales, these two rainfall patterns can be obtained when focussing on interannual and decadal frequencies. At these time scales, West African rainfall is modulated by SST changes, variations in the Inter-Tropical Convergence Zone position and land-atmosphere interactions (Giannini et al. 2005). Regarding the SST modulation, a low frequency mode showing contrasting interhemispheric SST anomalies has been identified in relation to Sahelian anomalous rainfall (Folland et al. 1986, 1991; Rowell et al. 1995; Joly et al. 2007). There are also two observed high frequency SST anomalous patterns: the Atlantic Equatorial Mode (Zebiak 1993) related to the dipolar rainfall pattern; and a Pacific El Niño-like mode associated with Sahelian rainfall (Rowell et al. 1995; Fontaine and Janicot 1996; Ward 1998; Joly et al. 2007).

Previous works have focused on the isolated impact of the different oceanic basins over West African rainfall patterns. It has been shown that years with a stronger tropical Atlantic influence tend to have the so-called anomalous 'dipole' rainfall pattern (Ward 1998; Vizy and Cook 2001; Losada et al. 2010). For the tropical Pacific, some authors have pointed out that years with larger ENSO impact tend to be associated with same-signed rainfall anomalies over West Africa (Ward 1998; Janicot et al. 2001; Rowell 2001; Giannini et al. 2003). Moron et al. (2003) showed that some AGCMs also reproduce the link between a positive ENSO phase and a weak West African Monsoon, a link that is only significant after the 1970s (Janicot et al. 2001). Out of the tropics, positive Mediterranean SST anomalies have been related to positive rainfall anomalies over the Sahel through an increase of evaporation and southward moisture advection (Rowell 2003; Jung et al. 2006; Fontaine et al. 2010).

Nevertheless, these SST patterns seem to operate differently depending on the sequence of years analysed. For example, the Pacific influence on Sahelian rainfall is conditioned to whether pre- or post-1970s years are studied (Janicot et al. 2001). In this way, depending on the analysed time period, different works lead to different conclusions. For instance, observational studies that consider only the period after the climate shift (e.g. Polo et al. 2008; for the period 1979-2001) obtained two separated rainfall patterns for the West African Monsoon season, one associated with the Guinea Gulf, and the other one with the Sahel. Conversely, other classical studies, using time series for the whole second half of the 20th century obtained a dipole of precipitation between the Guinea Gulf and the Sahel as one of the leading rainfall patterns of West African rainfall. Examples are Motha et al. (1980), whose study covers the period 1968-1975, or the work of Janowiak (1988), who used data for the 1927-1973 period.

The interpretation of all these results needs further analysis of the SST-West African variability for different periods. This idea is reinforced because one of the major recent signature of climate change is the rapid global warming from 1975 onwards (Trenberth et al. 2007). In addition to this global increase in temperature, the 1976-1977 winter season was marked by an abrupt change in the Pacific Ocean (Miller et al. 1994). Within the framework of this Climate Shift (Graham 1994; Cane et al. 1997), other changes have been described in different climate phenomena, like the change in the evolution of ENSO events (Trenberth et al. 2002), and the weakening of the ENSO-Indian Monsoon connection (Kucharski et al. 2007, 2008; Kumar et al. 1999). Also, recent observational analysis have pointed out that from the early 1970s, the tropical Atlantic and Pacific Niño modes show strong anticorrelation in summer (Polo et al. 2008) and that the Atlantic is able to enhance the next winter Pacific ENSO mode (Rodríguez-Fonseca et al. 2009). In relation to this latter finding, the Guinean rainfall variability has started to be linked with Pacific ENSO, as it was in the first decades of the 20th century (Joly and Voldoire 2010).

Whether or not the recent climate shift could have had an influence on the anomalous West African rainfall patterns is an interesting task that has not been addressed yet, and it is the first aim of this study.

The second aim of this work is to evaluate the reliability of five AGCMs and the multimodel approach in reproducing interannual variability of West African rainfall, with especial emphasis on the SST-West African rainfall relationships. In spite of the biases described in several of the AGCMs (Tennant 2003), given the observed SST evolution as boundary conditions, AGCMs can simulate the basic pattern of rainfall trends in the second half of the 20th century (Hoerling et al. 2006; Rowell et al. 1995; Bader and Latif 2003; Giannini et al. 2003; Haarsma et al. 2005; Kamga et al. 2005; Lu and Delworth 2005; 
Caminade and Terray 2010). But, in addition to the reliability of the models in simulating decadal trends of precipitation over West Africa, it would be also desirable that AGCMs could show skilful interannual variability. Results of this work will give some insights about this skilfulness and the problems of the models in simulating the multidecadal change of the interannual variability.

To this twofold aim, we analyse the observations and the results obtained in five different AMIP-type simulations performed with five different atmospheric models using as boundary conditions observed SSTs from the common period 1957-1998. These models, involved in the European project African Monsoon Multidisciplinary Analyses (AMMA-EU), are: ARPEGE, ECHAM4, ECHAM5, LMDZ, and UCLA models.

To study the change in variability after the climate shift of the 1970s, two different time-periods have been chosen for the analysis of rainfall variability. The whole common period is divided in two sub-periods, 1957-1978 and the dryer 1979-1998, which is also characterized by a better observational data due to the use of satellite measurements (e.g. CMAP data set, Xie and Arkin 1997). Especially, the better availability of observational data over the oceans in the 'satellite-period' helps to analyse the rainfall variability associated with changes in the oceanic Inter-Tropical Convergence Zone.

The paper is divided as follows: Sect. 2 presents the methodology and data, Sect. 3 shows the main results regarding West African modelled rainfall simulation (Sect. 3.1), interannual variability of rainfall (Sect. 3.2), and basin per basin SST - precipitation co-variability modes with its multidecadal changes (Sect. 3.3). Finally, Sect. 4 presents a summary of results and our conclusions.

\section{Data and methodology}

\subsection{Simulations}

To study the reliability of the AGCMs in reproducing the seasonal cycle and the variability of the West African Monsoon under Sea Surface Temperature (SST) forcing, five different AGCMs involved in the AMMA-EU project have been run using as boundary conditions the observed SSTs over the second half of the 20th century. The main characteristics of these five models are summarized in Table 1. ARPEGE and ECHAM5 models were driven by HadISST1 data set (Rayner et al. 2003). ECHAM4 model was forced by GISST data set (Rayner et al. 1996), which is an earlier version of HadISST1 data set. The main differences between both data sets are discussed by Rayner et al. (2003). LMDZ model was driven by AMIP II SST boundary conditions. These are based on the GISST data set and use the OI SSTs (Reynolds and Smith 1994; Reynolds et al. 2002) for the recent period. See Fiorino (2000) for more details on the construction of the AMIP II SST boundary conditions. UCLA model was driven by ERSSTv2 data set. Smith and Reynolds (2004) describe this data set in detail and discuss its differences with HadISST1 data set. The data sets present a similar interannual variability in the regions of interest for this article. The correlations of indices like the Atlantic 3 or the El Niño 3 are above 0.9 among data sets.

Some of the models were run in ensemble mode while, for other models, only one realization was available. The potential of the so-called multimodel ensemble method (Krishnamurti et al. 2000a, b) was also explored. Its variables were computed by averaging the outputs given by each model, taking into account the average field for those models with several runs before computing the overall multimodel mean. The common period for all the models was 1957-1998.

\subsection{Observations}

The observed data used to evaluate the simulations are: the monthly observed precipitation from the Climate Research Unit (CRU, Hulme 1992), and the monthly CPC Merged Analysis of Precipitation (CMAP, Xie and Arkin 1997).

\subsection{Methodology}

Due to the diversity of rainfall regimes over West Africa, rainfall anomalies are standardized prior to the analysis, using the corresponding monthly standard deviation:

$\mathrm{a}_{\mathrm{ij}}=\frac{\mathrm{r}_{\mathrm{ij}}-\mathrm{m}_{\mathrm{i}}}{\mathrm{s}_{\mathrm{i}}}$

where $\mathrm{j}$ denotes the index for the year, $\mathrm{i}$ the index for the month, $r_{i j}$ and $a_{i j}$ are the raw and standardized anomalous rainfall for month $i$ of year $j$, and $m_{i}$ and $s_{i}$ are the monthly mean and standard deviation for month $i$.

On the one hand, Empirical Orthogonal Function (EOF) analysis (von Storch and Navarra 1995) was applied over the West African domain (defined here as $21.25^{\circ} \mathrm{W}-$ $\left.33.75^{\circ} \mathrm{E}, 6.25^{\circ} \mathrm{S}-31.25^{\circ} \mathrm{N}\right)$ to extract the modes of rainfall variability. Only rainfall standardized anomalies from June to September were taken into account. The 4 month sequence of standardized anomalies were retained for each year. The anomalies were not detrended and the analysis was applied separately to both sub-periods: 1957-1978 and the dryer 1979-1998. In this way, a sequence of 88 (80) months entered the analysis in the first (second) sub-period. The analysis was applied by diagonalizing the covariance matrix of standardized rainfall. Studies performed by other authors differ from this work in not considering monthly 
Table 1 Description of the five models involved in the AMMA-EU intercomparison exercise

\begin{tabular}{|c|c|c|c|c|c|c|c|}
\hline Label & AGCM & Members & Levels & $\begin{array}{l}\text { SIC (Sea Ice } \\
\text { Concentrations) }\end{array}$ & $\begin{array}{l}\text { Boundary } \\
\text { Conditions }\end{array}$ & $\begin{array}{l}\text { Resolution } \\
\text { (lon-lat) }\end{array}$ & $\begin{array}{l}\text { Model } \\
\text { references }\end{array}$ \\
\hline APRPEGE & $\begin{array}{c}\text { ARPEGE V3 } \\
\text { IPCC AR4 }\end{array}$ & 1 & 45 & $\begin{array}{l}\text { HadISST1 (Rayner } \\
\text { et al. 2003) }\end{array}$ & HadISST1 & $\begin{array}{l}\text { T42, approx. } \\
2.80 \times 2.80\end{array}$ & $\begin{array}{l}\text { Déqué et al. } \\
\text { (1994) }\end{array}$ \\
\hline ECHAM4 & ECHAM 4 & 1 & 42 & $\begin{array}{l}\text { GISST (Rayner et al. } \\
\text { 1996) }\end{array}$ & GISST & $\begin{array}{l}\text { T30, approx. } \\
3.75 \times 3.75\end{array}$ & $\begin{array}{l}\text { Ruti et al. } \\
\text { (2006) }\end{array}$ \\
\hline ECHAM5 & ECHAM 5 & 5 & 31 & HadISST1 & HadISST1 & $\begin{array}{r}\text { T106, approx. } \\
1.13 \times 1.12\end{array}$ & $\begin{array}{l}\text { Roeckner et al } \\
\text { (2003) }\end{array}$ \\
\hline LMDZ & LMDZ 4 & 6 & 19 & $\begin{array}{l}\text { AMIP II (Fiorino } \\
\text { 2000) }\end{array}$ & SST AMIP II & $\begin{array}{l}96 \times 71 \text { approx } \\
3.75 \times 2.50\end{array}$ & $\begin{array}{l}\text { Hourdin et al. } \\
\text { (2006) }\end{array}$ \\
\hline UCLA & UCLA 7.3 & 4 & 29 & Climatology & $\begin{array}{l}\text { ERSSTv2 (Smith and } \\
\text { Reynolds 2004) }\end{array}$ & $\begin{array}{l}144 \times 89 \\
2.50 \times 2.00\end{array}$ & $\begin{array}{l}\text { Richter et al. } \\
\text { (2008) }\end{array}$ \\
\hline
\end{tabular}

summer sequences but seasonal means (Giannini et al. 2003). Also, other authors do not apply standardization to the anomalies (Giannini et al. 2003) and the period of years taken into account is different (Ward 1998).

On the other hand, to extract those time varying SST structures coupled to West African rainfall, the methodology of Extended Maximum Covariance Analysis (EMCA, Polo et al. 2008) was applied to the West African precipitation and the anomalous SST of each of the ocean basins. This methodology is an extension of the Maximum Covariance analysis (MCA, or SVD Bretherton et al. 1992; Frankignoul and Kestenare 2005) but considering more than one lag in the predictor array. The methodology is based in obtaining the singular value decomposition of the covariance matrix formed by:

$$
\begin{array}{r}
\mathrm{C}_{\mathrm{ik}}=\sum_{\mathrm{j}=1}^{\mathrm{n}_{\mathrm{t}}} \frac{\mathrm{Y}_{\mathrm{ij}} \cdot \mathrm{Z}_{\mathrm{kj}}}{\mathrm{n}_{\mathrm{t}}-1} ; \quad \mathrm{i}=1, \ldots, \mathrm{n}_{\mathrm{y}} \\
\mathrm{j}=1, \ldots, \mathrm{n}_{\mathrm{t}} ; \quad \mathrm{k}=1, \ldots, \mathrm{n}_{\mathrm{z}}
\end{array}
$$

where $\mathrm{Y}$ and $\mathrm{Z}$ are the predictor (SST) and predictand (rainfall) fields, $\mathrm{n}_{\mathrm{t}}$ the time dimension, $\mathrm{n}_{\mathrm{y}}$ the extended predictor dimension (defined as the spatial dimension times the number of lags) and $\mathrm{n}_{\mathrm{z}}$ the spatial dimension of the predictand field.

As in the EOF analysis, in this work the sequence of four summer months (June to September) of standardized rainfall anomalies was used as the predictand field. Therefore, $\mathrm{n}_{\mathrm{t}}$ is four times the number of years that enter the analysis. The value of $n_{z}$ is the number of rainfall grid points covering the West African domain (defined above), while the first dimension of the predictor field $\left(\mathrm{n}_{\mathrm{y}}\right)$ is an extension of its spatial dimension (number of grid points in the selected SST domain: $n_{\mathrm{s}}$ ) that takes into account all lags ( 8 in our case). Consequently, $\mathrm{n}_{\mathrm{y}}=\mathrm{n}_{\mathrm{s}} * 8$. The predictor field consisted in 4 month sequences of detrended, nonstandarized, SST anomalies. The time lag was 1 month and lags -4 (February to May sequence) to +3 (September to December sequence) were used in the analysis.
The EMCA methodology allows us to have the whole picture of the evolution of the anomalous SST pattern that highly co-varies with the summer (June to September) precipitation, giving a realistic persistence feature from winter (February to May) to next fall (September to December). In this way, the SST expansion coefficient could be defined as a dynamical predictor within the seasonal cycle. As in the classical MCA, each mode comprises different spatial structures and time series (expansion coefficients). For more details, interested readers are referred to Polo et al. (2008).

To analyse the changes in the coupled and uncoupled variability modes of West African rainfall after the climate shift of the late 1970s, the whole period (1957-1998) has been divided in two sub-periods: 1957-1978 and 1979-1998. This cutting date allows the use of satellitebased rainfall data in the second period. This homogeneous data set (CMAP) ensures the spatial continuity of the rainfall patterns, allowing the analysis of the oceanic part of West African rainfall variability. The EOF and EMCA analysis has been applied to both sub-periods separately. This procedure excludes multidecadal variability because the maximum length of the analysed time series is 22 years. The same results are obtained if the time series are previously high-frequency filtered (not shown).

\subsection{Statistical significance of the results}

A two-tailed t-test is used to evaluate the $95 \%$ statistical significance of the EOF patterns. For the co-variability modes, the results are shown in terms of homogeneous and heterogeneous regression maps for the SST sequence and for the summer precipitation field, respectively. Only those areas that are $95 \%$ statistically significant (evaluated with a t-test) are mapped. The robustness of the modes is assessed using the following Monte Carlo test: the time series are shuffled and the EMCA analysis is applied 100 times to obtain a probability density function for the squared 
covariance fraction and the correlation coefficients between the expansion coefficients. The original squared covariance fraction and the correlation coefficient indices are compared to the corresponding probability density functions.

To highlight the change in the co-variability modes, the difference between the SST (precipitation) homogeneous (heterogeneous) patterns in both periods is computed. To test the level of significance of this difference, another Monte Carlo test is used. SST homogeneous and precipitation heterogeneous maps are computed as the regression of the SST and precipitation fields onto the expansion coefficient of the SSTs. To test the significance between these regression maps (1979-1998 period minus 1957-1978) for a given point, the time series at that point and the expansion coefficient are permuted independently and a new regression is calculated for both periods separately. Then, a new difference is computed and this procedure is repeated 100 times to build a probability density function of differences. The original difference is tested against the probability density function to asses its significance.

\section{Results}

\subsection{Simulated precipitation}

Figure 1 presents the Hovmoller plot of the precipitation averaged over the $10^{\circ} \mathrm{W}-10^{\circ} \mathrm{E}$ longitudinal band for the five different simulations and the multimodel ensemble (first three rows) together with the observations from CRU data set for the 1957-1998 period. Parallel to this, Fig. 2 displays the horizontal map of the corresponding summer (July to September) seasonal averaged rainfall.

In accordance with other works (Sultan and Janicot 2000, 2003), the pattern derived from the observations displays the succession of a first rainy sequence (the preonset) along the Guinea Coast during spring, followed by a weakened convection transition period at the end of June/beginning of July corresponding to the summer monsoon onset (Fig. 1). During this transition the Inter-Tropical Convergence Zone moves abruptly from the latitude $5^{\circ} \mathrm{N}$ up to $10^{\circ} \mathrm{N}$ (Sultan and Janicot 2003). The precipitation simulated by the multimodel ensemble shows a first maximum of precipitation in May and a northward migration of rainfall from $4^{\circ} \mathrm{N}$ in May-June to $10^{\circ} \mathrm{N}$ in August (Fig. 1).

All models reproduce a maximum of rainfall centred over the Guinean region $\left(3^{\circ}-6^{\circ} \mathrm{N}\right)$ in spring (the preonset) and simulate a northward progression of rainfall from spring to summer (the monsoon onset) (Fig. 1). However, differences among models and with the observations exist. Rainfall is overestimated over Guinea in spring by the ARPEGE, ECHAM5 and UCLA models (Fig. 1). For the same models the latitude of maximum rainfall shifts from $3^{\circ} \mathrm{N}$ in May to $9^{\circ}-12^{\circ} \mathrm{N}$ in June, a month earlier than in the observations (Fig. 1). The LMDZ shows a small latitudinal rainfall shift from $6^{\circ} \mathrm{N}$ in June to $9^{\circ} \mathrm{N}$ in July, which is associated to a lower meridional extension of the rainfall belt compared with the observations (Fig. 1).

ECHAM5 and UCLA models overestimate summer rainfall over West Africa, while ECHAM4 model underestimates it (Fig. 2), which is consistent with a less pronounced Sahara heat low and slower low-level southwesterly winds for this model than in ERA40 or NCEP reanalysis (Losada et al. 2010). ECHAM5 and LMDZ models present a too narrow belt of summer rainfall while the belt is too wide for ARPEGE and UCLA ones (Fig. 2). Note that there are a lot of differences between ECHAM4 and ECHAM5 in West African climate, which may be due to the different version of the model but also to the very high resolution (T106) in ECHAM5.

\subsection{Rainfall variability patterns}

The observational EOF analysis done for the 1957-1978 period reveals that the leading principal component (PC) projects onto a precipitation pattern that has its maximum loadings over Sahel (11\% of explained variance; Fig. 3a). The regression map of the second PC shows its main loadings over Guinea (7\% of explained variance; Fig. 3h), which has also been shown by other authors (Polo et al. 2008). The second EOF exhibits interannual signals in the PC time series (Online Resource 1) and, when the observed SSTs are regressed onto the corresponding PC, it shows positive loadings over the Equatorial Atlantic (not shown). Nevertheless, when performing the analysis with nonstandardized data, the modes appear in a reversed order, this is, maximum loadings over Guinean and Sahelian regions for the first and second mode respectively (not shown), in agreement with other works (Giannini et al. 2003). From our results, during the 1957-1978, most of the interannual rainfall variability was concentrated over Sahel, while the second EOF is related to Guinean rainfall (Fig. 3a, h). Although several authors have pointed out that a significant part of the interannual variability of West African anomalous rainfall is due to the opposite evolution between central Sahelian and Guinean rainfall indices (Janicot 1992a; Fontaine et al. 1995; Janicot et al. 1996), our results separate the Guinean and Sahelian rainfall into two different modes, even when performing the VARIMAX rotation (Kaiser 1958) (not shown). Giannini et al. (2003) showed a separation of Guinean and Sahelian rainfall too, using an extended period to compute the nonrotated EOFs of the seasonal means. Also, Polo et al. (2008) found two separated patterns describing the Guinean and Sahelian rainfall variability. 
Fig. 1 Latitude-time precipitation $(\mathrm{mm} /$ day) diagrams for the five simulations, the multimodel ensemble of simulations, and CRU data set in the whole 1957-1998 period. The precipitation has been averaged over the longitudinal area $10^{\circ} \mathrm{W}$ to $10^{\circ} \mathrm{E}$
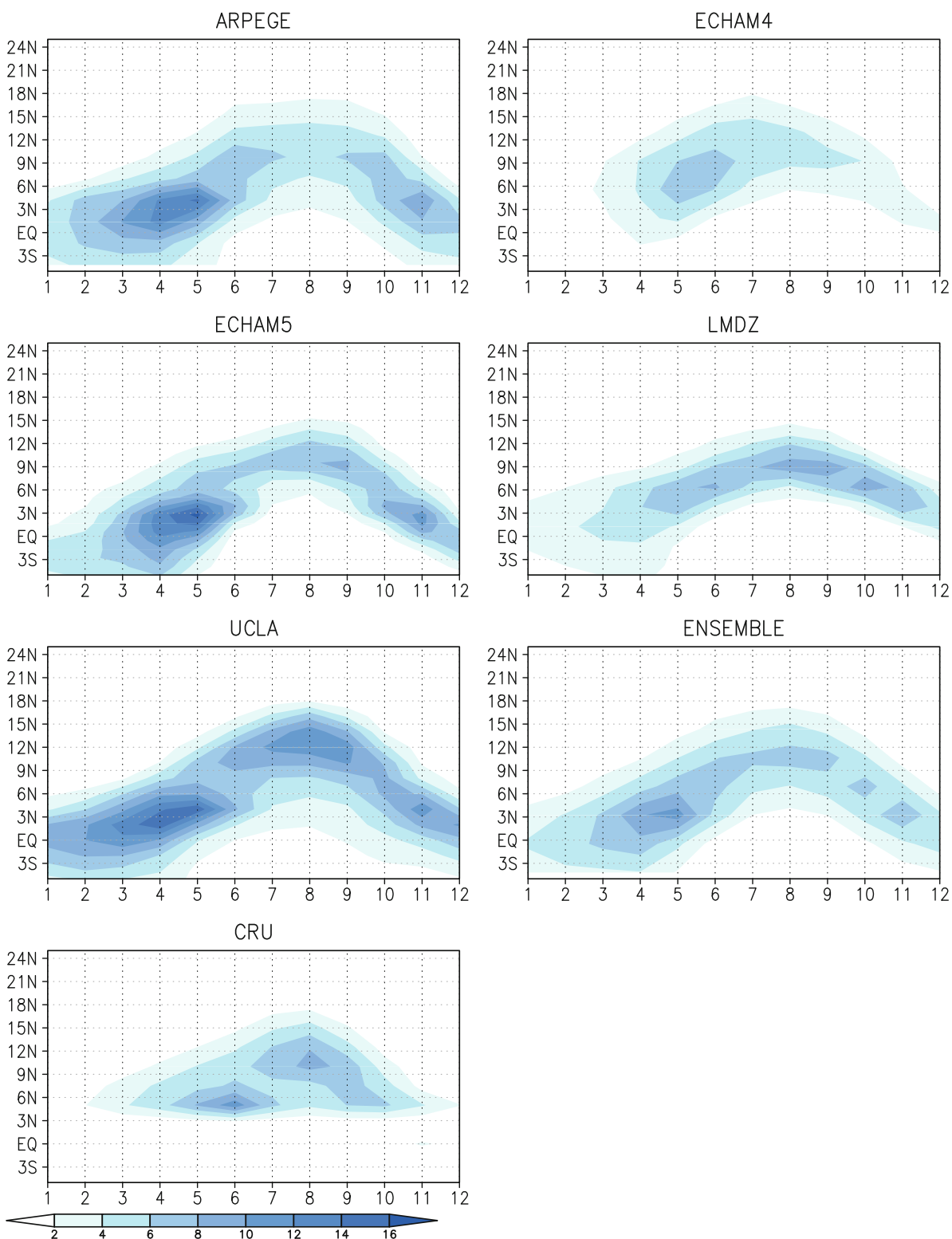

Regarding the simulated response, the second mode of most models shows its main loadings over Guinea, similarly to the observations (Fig. 3). The associated PCs show 99\% significant correlation (according to a two-tailed t-test) with the observed one for most models (Table 2). When the observed SST are regressed onto the corresponding PC, they show positive loadings in the Equatorial Atlantic (not shown). The UCLA model is an exception. It is its first mode which shows higher loadings over Guinea and an associated PC significantly correlated with the observed second one (Table 2).

Regarding the first mode, most models show high loading over the Sahel, like the observations (Fig. 3). However, the correlation of the associated PC and the observed one is only 95\% significant (according to a twotailed t-test) for the LMDZ model. The UCLA model is again an exception. The PC associated to its second EOF is significantly correlated with the first observed one. This result is also obtained for the second period (not shown).

In summary, for both periods models tend to show a leading mode with loadings over the Sahel, and a second EOF mainly related to the variability of Guinean rainfall. For most models, the PC associated with the mode related to Guinean rainfall is significantly correlated to the one obtained from observations, suggesting that Guinean rainfall is mainly driven by SSTs, especially in the Equatorial Atlantic. Conversely, the observed first mode, related to Sahel rainfall, is less well captured by the models, hinting to a higher degree of internal atmospheric variability. In addition, interannual variability of Sahelian precipitation has been shown to be partially driven by SST variability in remote oceans (Rowell 2001; Janicot et al. 2001; Mohino 

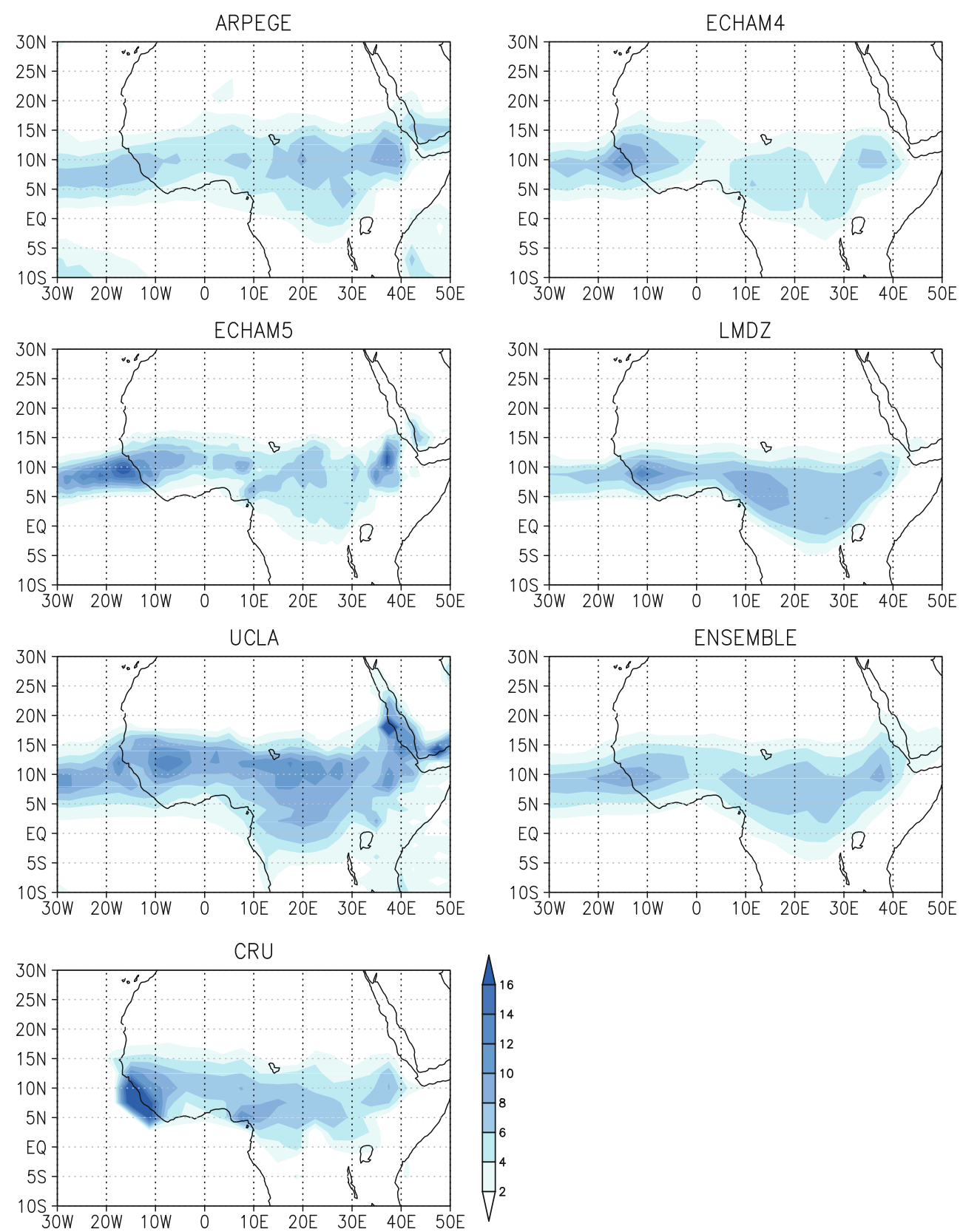

Fig. 2 July to September averaged precipitation (mm/day) from the five models, the multimodel ensemble, and CRU data set for the whole 1957-1998 period

et al. 2011). Thus, the reduced skill of models in simulating Sahelian variability compared to Guinean one also suggests that models show more reliability in their response to nearby SST anomalies and more difficulties modelling remote teleconnections.

\subsection{SST-rainfall coupled modes}

Once the rainfall variability patterns have been discriminated, we investigate basin per basin the characteristics of the leading EMCA coupled interannual mode computed between SST and June to September West African rainfall anomalies for the observations and simulations considering both periods.

In this paper we focus on the results that are statistically robust, primarily those for the Atlantic and Pacific basins in both periods and the Mediterranean basin in the second period. The robustness of the modes is determined by analysing the probability distribution function of the squared covariance and the correlation coefficient between the expansion coefficients when repeating the analysis under Monte Carlo conditions. 

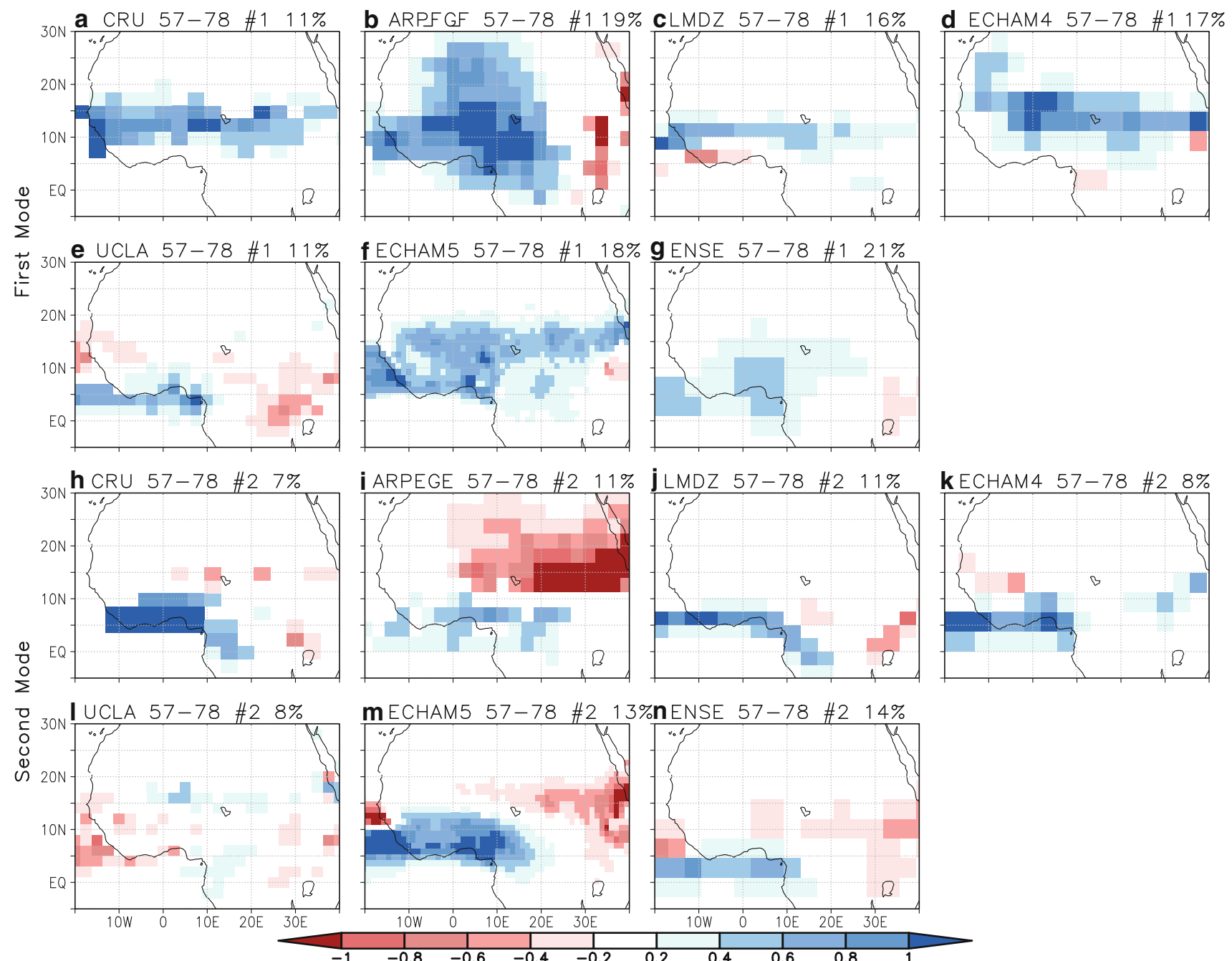

Fig. 3 Spatial pattern of the first EOF mode in the 1957-1998 period for: a CRU data set; b ARPEGE, c LMDZ, d ECHAM4, e UCLA and f ECHAM5 models and $\mathbf{g}$ multimodel ensemble. Spatial pattern of the second EOF mode in the 1957-1998 period for: h CRU data set;

Table 2 Correlations of modelled and observed principal components associated to the two first modes of the EOF analysis in the 1957-1978 period

\begin{tabular}{llllll}
\hline Model EOF & \multicolumn{2}{l}{ CRU \#1 } & & \multicolumn{2}{l}{ CRU \#2 } \\
\cline { 2 - 3 } \cline { 6 - 7 } & $\# 1$ & $\# 2$ & & $\# 1$ & $\# 2$ \\
\hline APRPEGE & 0.05 & 0.05 & & $0.32^{* *}$ & 0.03 \\
ECHAM4 & 0.10 & -0.13 & & $-0.26^{*}$ & $0.28^{* *}$ \\
ECHAM5 & 0.07 & -0.08 & & 0.15 & $0.52 * *$ \\
LMDZ & $0.26^{*}$ & 0.01 & & -0.13 & $0.54 * *$ \\
UCLA & 0.13 & $0.36^{* *}$ & & $0.46^{* *}$ & -0.12 \\
ENSEMBLE & 0.06 & 0.00 & & $0.29 * *$ & $0.48^{* *}$
\end{tabular}

Single (double) asterisks mark correlations statistically significant at the $95 \%$ (99\%) level using a two-tailed t-test

i ARPEGE, $\mathbf{j}$ LMDZ, $\mathbf{k}$ ECHAM4, $\mathbf{l}$ UCLA and $\mathbf{m}$ ECHAM5 models and $\mathbf{n}$ multimodel ensemble. Units are $\mathrm{mm} /$ day per standard deviation of the associated PC. The explained variance is given in the title. Only 95\% significant results (according to a t-test) are shown

The interannual Indian Ocean-West African precipitation co-variability modes are not robust and are not shown here.

\subsubsection{Atlantic SST-West African precipitation}

Figure $4 \mathrm{a}$ and $\mathrm{b}$ summarize the results for the first mode of co-variability between observed West African precipitation and SSTs in the Atlantic basin for the two periods. It shows the seasonal evolution of the anomalous SST pattern (first to third columns) together with the associated June to September anomalous rainfall pattern over West Africa (fourth column). The expansion coefficients for the SST and the rainfall are shown in the fifth column. The statistical 

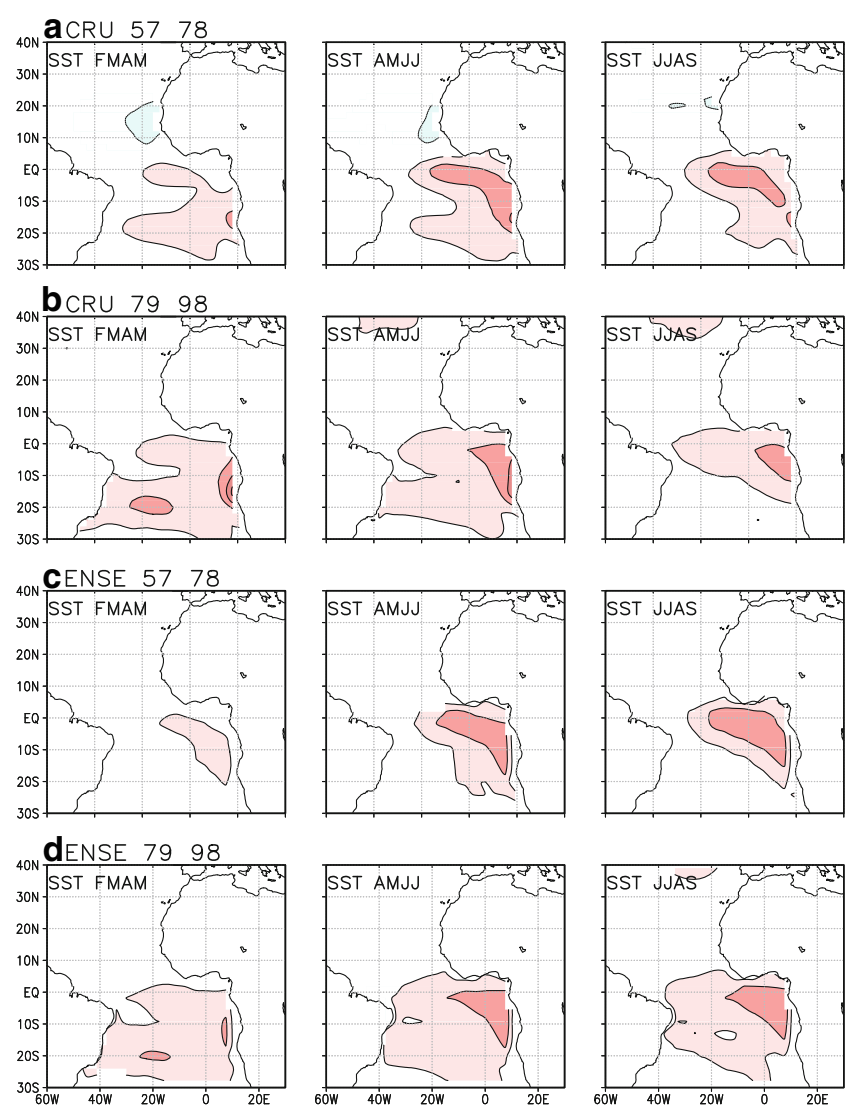

SST

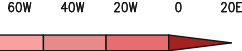

Fig. 4 First co-variability mode (calculated using EMCA methodology) between observed July to September (JJAS) standardized precipitation over West Africa and Atlantic SSTs. Homogeneous SST maps (left) are shown for the February to May (FMAM) (first column), April to July (AMJJ) (second column) and July to September (JJAS) (third column) seasons. Heterogeneous JJAS precipitation maps are shown in the fourth column. Units are $\mathrm{mm}$ /day per standard deviation of SST expansion coefficient, and K per standard deviation of SST expansion coefficient, respectively. Only 95\% significant anomalies are shown (according to a t-test). The SST (rainfall)

robustness of the results are shown with the probability density functions of the squared covariance fraction and correlation scores between the expansion coefficients (sixth column). For comparison, the results of the multimodel ensemble are also shown (Fig. 4c, d).

For the 1957-1978 period, the first co-variability mode relates the warm phase of the Equatorial Atlantic mode with a dipole structure in West African rainfall, with higher precipitation in the Guinea Gulf coast and less precipitation in the Sahel (Fig. 4a). The mode explains $41 \%$ of the squared co-variance fraction. Nevertheless, for the 1979-1998 period there is no rainfall dipole and warm anomalies over the Equatorial Atlantic are related only to an increase of precipitation over Guinea and south Sahel (Fig. 4b). This result is also obtained with CMAP data set
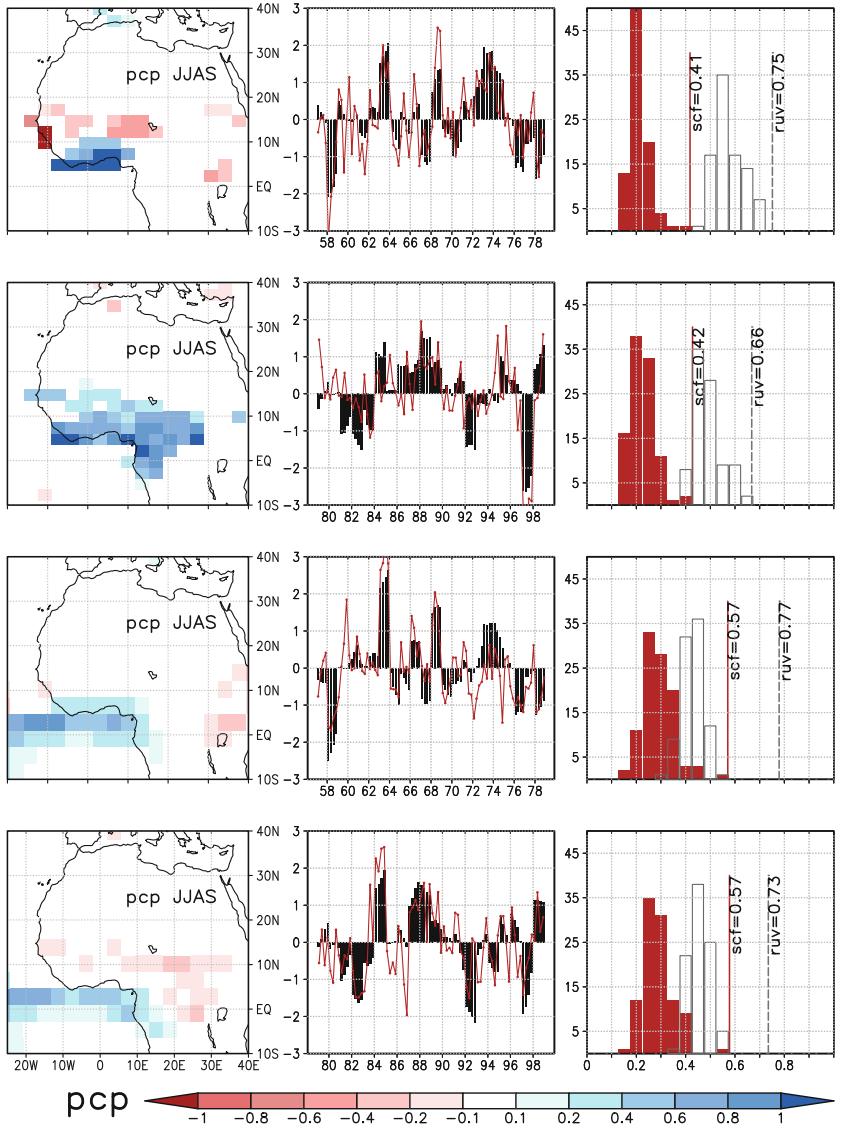

expansion coefficients are shown in black (red) in the fifth column. Probability density functions calculated by Monte Carlo technique are shown in the sixth column for the squared co-variance fraction ( $s c f)$ (red solid bars) and correlation coefficient (ruv) (dark grey open bars). The original squared covariance fraction and correlation coefficients are indicated as red and dark grey lines, respectively. The co-variability modes are shown for: a CRU data set in the 1957-1978 period, b CRU data set in the 1979-1998 period, c ensemble multimodel in the 1957-1978 period and d ensemble multimodel in the 1979-1998 period

(not shown). The observed connection goes along the seasonal cycle and can be observed with at least 2 months in advance (Polo et al. 2008). The corresponding squared covariance fraction explained is $42 \%$ ( $31 \%$ for CMAP data set).

Although similar for both periods, the evolution of the SSTs presents some differences. The positive SST anomalies over the Equatorial Atlantic are more zonally elongated in the first period (Fig. 4a) than in the second one (Fig. 4b). In accordance with Robertson et al. (2003) and Polo et al. (2008), from the 1970s the SST anomalies are originated at the Angola-Benguela upwelling region in late winter and propagate in an anticlockwise way from that region up to the Equator. The warming in the Angola upwelling region is more intense in the second period and 
the maximum anomalies during the peak phase extend more over the central equatorial basin in the first one (Fig. 4a, b).

The most striking differences between both periods in the SST and precipitation patterns can be seen in Fig. 5. The regressions of the global anomalous SST onto the SST expansion coefficient show that, while the Equatorial
Atlantic mode is independent of the rest of the basins in the 1957-1978 period (Fig. 5b), in the 1979-1998 period it appears along with opposite anomalies in the tropical eastern Pacific (Fig. 5a). This presence of different signed anomalies in both basins is a fingerprint of the connection that the Atlantic and Pacific El Niño events have shown after the 1970s (Rodriguez-Fonseca et al. 2009). In
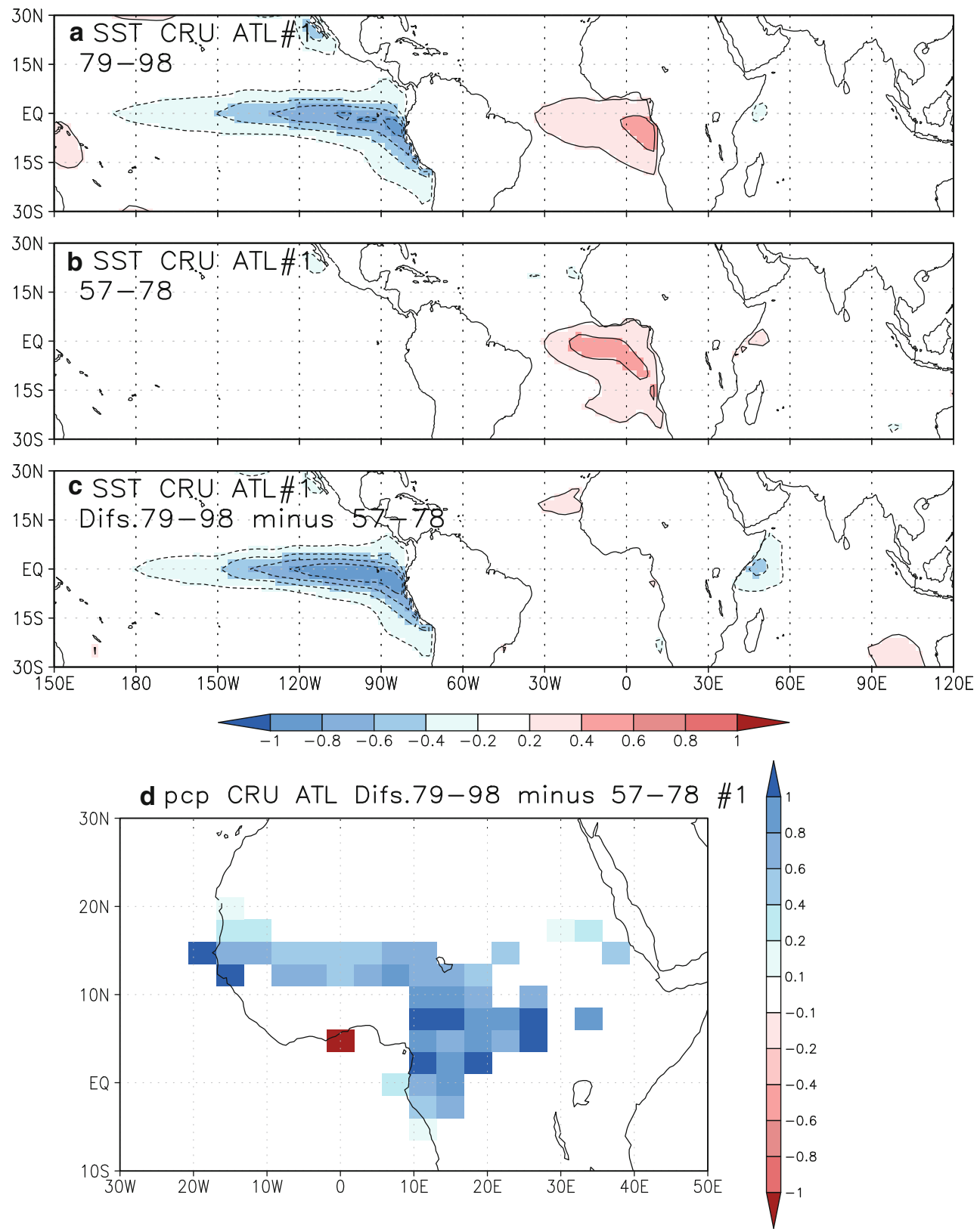

Fig. 5 Regression of tropical SSTs onto the SST expansion coefficient of the first co-variability mode between JJAS standardized precipitation over West Africa and Atlantic SSTs: a for CRU covariability mode in the 1979-1998 period and b for CRU covariability mode in the 1957-1978 period. Only 95\% significant anomalies (according to a t-test) are shown. Difference between the
CRU co-variability mode for 1979-1998 minus 1957-1978: c in tropical SST and d rainfall over West Africa. Only 95\% significant areas (according to a Monte Carlo test) are shown. Units are $\mathrm{mm} /$ day per standard deviation of SST expansion coefficient, and $\mathrm{K}$ per standard deviation of SST expansion coefficient, respectively 
addition, these results are also consistent with the statistical relationship that Guinean rainfall and ENSO have shown after the 1970s (Joly and Voldoire 2010).

The next step is to locate the regions where the covariability mode showed significant differences in rainfall and to confirm if the change in the relationship between West African rainfall and the Equatorial Atlantic mode is related to changes in the Atlantic SST pattern or in the global projection. Figure $5 \mathrm{c}$ and $\mathrm{d}$ show the difference between the 1979-1998 and the 1957-1978 SST and rainfall patterns, respectively. The change in the precipitation pattern is mainly located over the Sahel and Central Africa, between Congo and Chad, a result that could give more insights to the understanding of the changes in Sahelian rainfall from this decade. Nevertheless, the difference in the SST pattern indicates that this rainfall change is not related to significant SST changes over the equatorial Atlantic, but rather to anomalies in the eastern Pacific and western equatorial Indian basins. Following several observation and modelling studies, which have shown an anticorrelation between the SSTs in the Pacific and Indian basins and precipitation in the Sahel (Rowell 2001; Bader and Latif 2003; Mohino et al. 2011), these anomalies over the Pacific basin could partially explain the differences in precipitation over the Sahel.

Regarding the simulations, Fig. 6 shows the anomalous rainfall EMCA pattern in the 1957-1978 period for all models (left column) and the differences between the two periods (right column). The absence of significant differences in the Guinean region indicates that all models show a robust Atlantic-West African rainfall co-variability mode linking warm anomalies in the Equatorial Atlantic with positive anomalies of precipitation in the Guinea Gulf for both periods (Figs. 4c, d and 6). The squared covariance fraction varies from 38 to $57 \%$, showing the high relationship between the Equatorial Mode and West African rainfall variability. SST patterns similar to the observed ones, and alike evolution along spring and summer are found for the two periods (not shown). The correlations between SST expansion coefficients for model and observations is above 0.9 (not shown). Note that the models tend to show a dipole structure with negative loadings in the Sahel in the 1957-1978 period, as the observations (Fig. 4a), though it is only statistically significant for the LMDZ, UCLA and ECHAM4 models (Fig. 6). Vizy and Cook (2002) also point out that AGCMs have problems reproducing the dipole structure (e.g. Ward 1998), although their regional model (with higher resolution) is able to do it. Losada et al. (2010) have demonstrated that the response to an isolated Equatorial Mode is a dipolar structure due to the southward (northward) shift of the Inter-Tropical Convergence Zone for a warm (cold) Equatorial Atlantic mode.
Although in the observations there is a remarkable difference in the relationship between Sahelian rainfall and the Atlantic Equatorial mode before and after the 1970s (Fig. 5d), overall, models tend to fail when looking at these changes in the rainfall component of the EMCA modes (Fig. $6 \mathrm{f}-\mathrm{j}$ ). However, over the ocean all models consistently show an increase of rainfall after the 1970s between $7^{\circ} \mathrm{N}$ and $15^{\circ} \mathrm{N}$ in relation to a warm Atlantic Equatorial mode (Figs. 6f-j).

As suggested above, the observed absence of a dipolar rainfall pattern associated with the Equatorial SST mode during the period 1979-1998 could be due to the highest impact of concomitant ENSO events on West African rainfall (Janicot et al. 2001). The fact that the models simulate a more dipolar rainfall structure than the observation in this period could be due to a lack of reliability in simulating the indirect link with ENSO.

\subsubsection{Pacific SST-West African precipitation}

Figure $7 \mathrm{a}$ and $\mathrm{b}$ summarize the results for the first mode of co-variability between observed West African precipitation and Pacific SSTs for the two periods. The results for the multimodel ensemble are also shown (Fig. 7c, d). In the 1979-1998 period, the observed mode indicates a warming (cooling) in the tropical Pacific related to a decrease (increase) in precipitation over West Africa. This result is also obtained with CMAP data set (not shown). The mode explains $62 \%$ (46\% when using CMAP data set) of the squared covariance fraction.

For the 1957-1978 period, the observed precipitation mode, which explains less squared covariance fraction $(42 \%)$, is just determined by a few significant grid points (Fig. 7a) and not a solid pattern as in the second period. These areas are located mainly in the Southern and Eastern Sahel and show 95\% significant negative correlations with the tropical Pacific SST. This is in accordance with the enhanced influence of the tropical Pacific over the West African precipitation variability since the 1970s (Janicot et al. 2001).

The difference between the co-variability modes in both periods is highlighted in Fig. 8. The main change in the precipitation pattern is located in the eastern part of the Guinea Gulf, and in Central Africa (Fig. 8d). Note that the differences are calculated using CRU data set, which does not have information over the ocean, so it is logical to think in a continuity of this pattern over the equatorial Atlantic. The significant difference between the SST patterns for the two periods does not take place over the Pacific, but over the Equatorial Atlantic (Fig. 8c). This result suggests that the change in the precipitation pattern is related to the presence of concomitant anomalies in the Eastern Equatorial Atlantic region in the second period, 
Fig. 6 Heterogeneous precipitation maps for the 1957-1978 first co-variability modes between JJAS

standardized precipitation and Atlantic SSTs for: a ECHAM5, b LMDZ, c UCLA, d ECHAM4 and e ARPEGE models. The difference between 1979 and 1998 minus 1957 and 1978 heterogeneous maps are shown for the same models in plots $(\mathbf{f}-\mathbf{j})$. Only $95 \%$ significant regions (according to a t-test and a Monte Carlo test, respectively) are shown. Units are $\mathrm{mm} /$ day per standard deviation of SST expansion coefficient
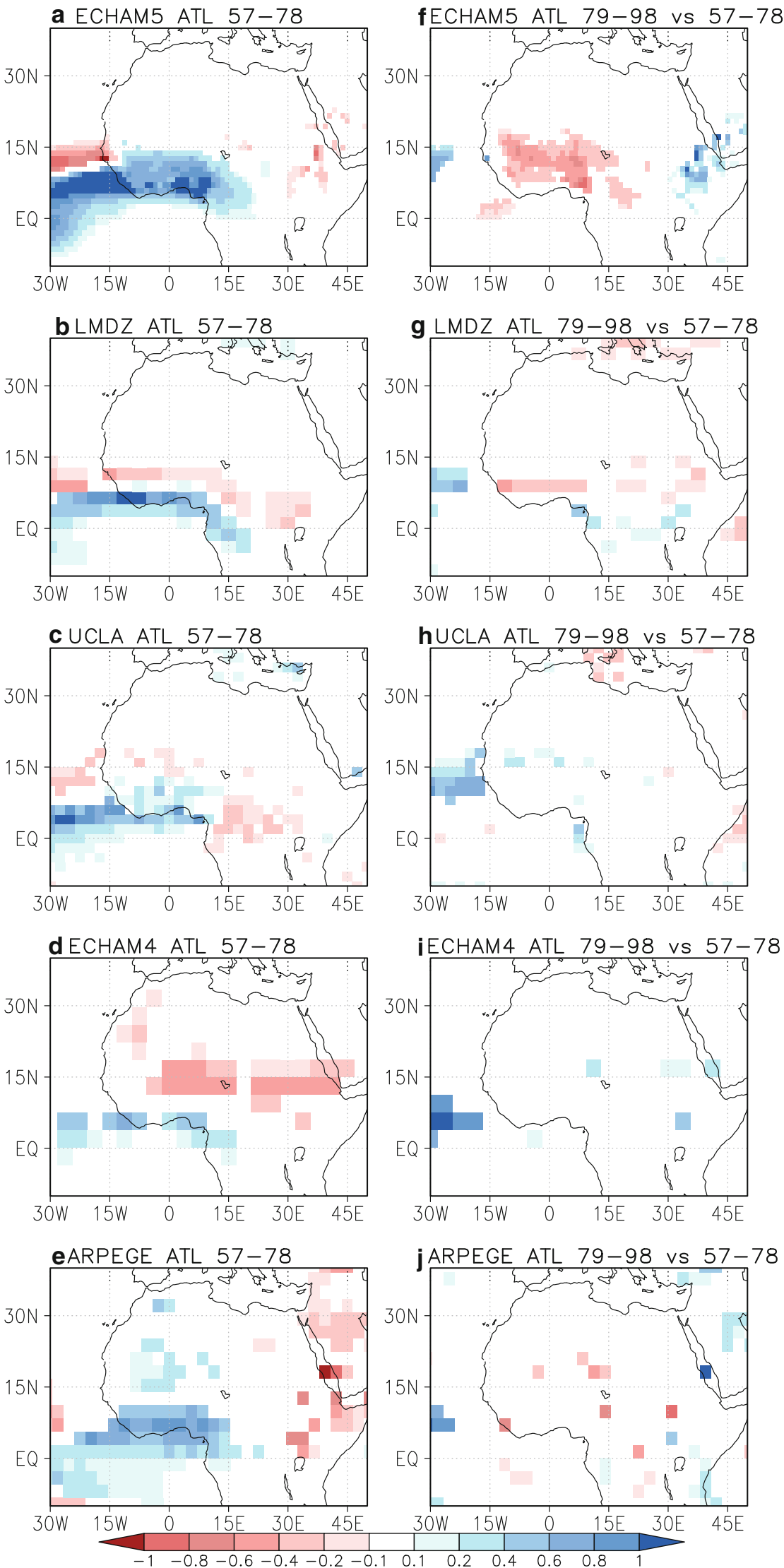

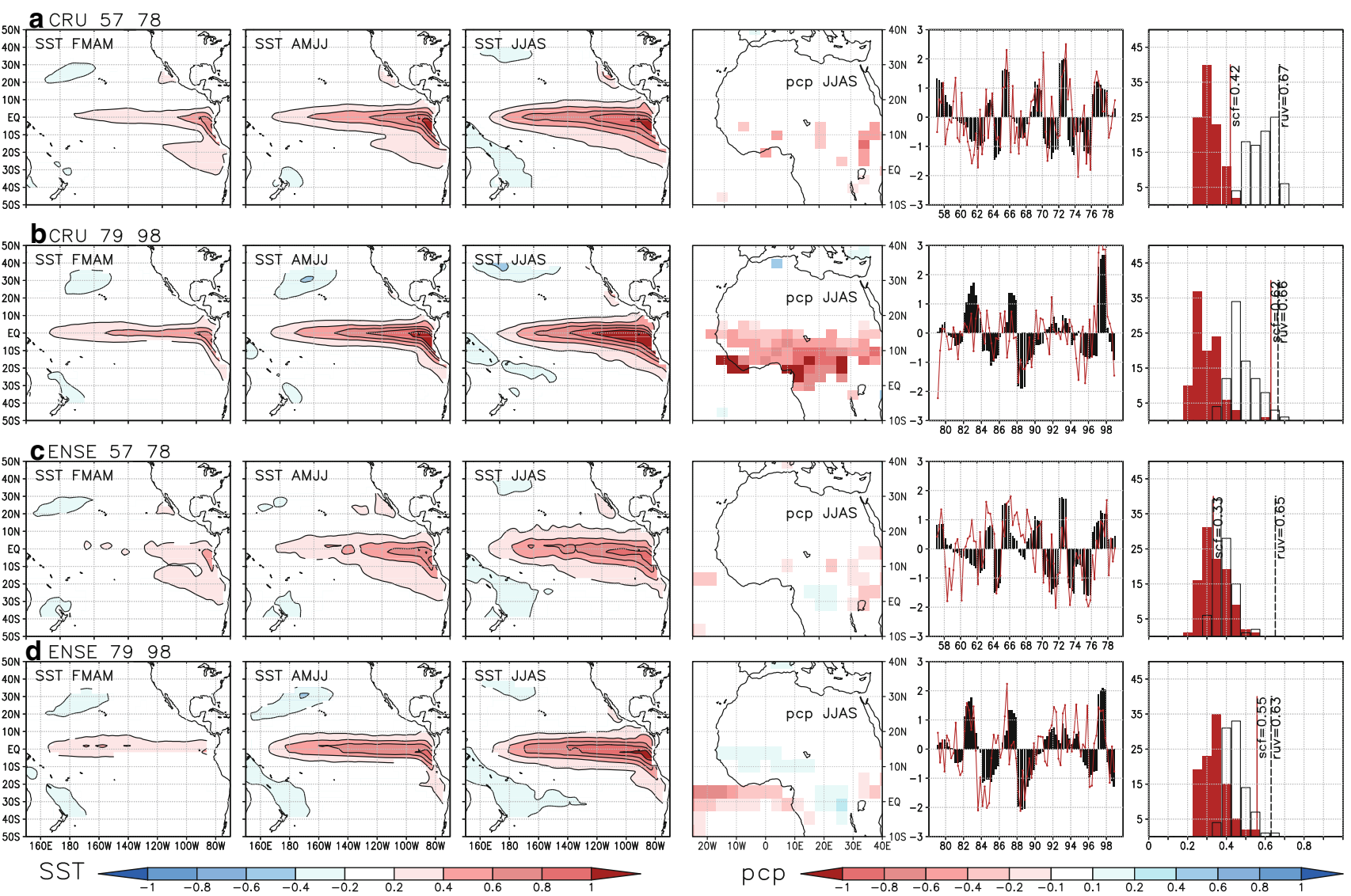

Fig. 7 Same as Fig. 4 but for the first co-variability mode between observed July to September (JJAS) standardized precipitation over West Africa and Pacific SSTs

that were absent in the first one (Fig. 8a, b). This is in agreement with the non-stationary behaviour of the Atlantic and Pacific El Niños relationship, recently reported by Rodriguez-Fonseca et al. (2009). These additional SST anomalies have been shown (see previous section) to have maximum impact over the Guinea Gulf through the modification of convection (Losada et al. 2010). Bader and Latif (2010) model's response to Atlantic SST anomalies shows a significant rainfall reduction along the Guinea Coast. The response of west African rainfall is mainly restricted along the Guinea Coast and there is no clear response in rainfall over the west Sahel.

Regarding the simulations, the multimodel ensemble shows a robust first co-variability mode only in the second period (Fig. 7c, d). The SST pattern and its evolution are coherent with the observed one, with correlations between model and observation expansion coefficients above 0.9, but the precipitation pattern is reversed over the Sahel. Among models, the fraction of explained squared covariance varies from 26 to $60 \%$. In the first period, models tends to show a negative anomaly over the Sahel in relation with warm anomalies over the tropical Pacific (Fig. 9a-e), in accordance with other observational and experimental studies (e.g. Folland et al. 1986; Palmer 1986; Rowell et al. 1995; Janicot et al. 1998, 2001; Rowell 2001; Giannini et al. 2003; Moron et al. 2003, 2004; Mohino et al. 2011). In addition, the UCLA, ECHAM4, ARPEGE and ECHAM5 models show a positive anomaly over the eastern Guinea Gulf.

Regarding the change in the co-variability modes, Fig. $9 \mathrm{f}-\mathrm{j}$ show the difference between the 1979-1998 minus 1957-1978 precipitation patterns for the models. Most models show a wetter Sahel and a dryer Guinea Gulf in the last period. As in the observations, the change in the modelled SST patterns does not project onto the Pacific basin but rather onto the Atlantic equatorial region (not shown). This colder anomaly in the Atlantic would strengthen the thermal gradient between the sea and the continent, driving the monsoon further north and, thus, explaining the dipole structure in Fig. $9 \mathrm{f}-\mathrm{j}$. Again, this result agrees with Losada et al. (2010) who pointed to the presence of a dipolar rainfall anomalous pattern over West Africa as the response to an isolated Equatorial Mode. It also agrees with the study by Joly and Voldoire (2010), who pointed out that during the years in which the Guinea Gulf rainfall is not related to ENSO, Sahelian and Guinean 

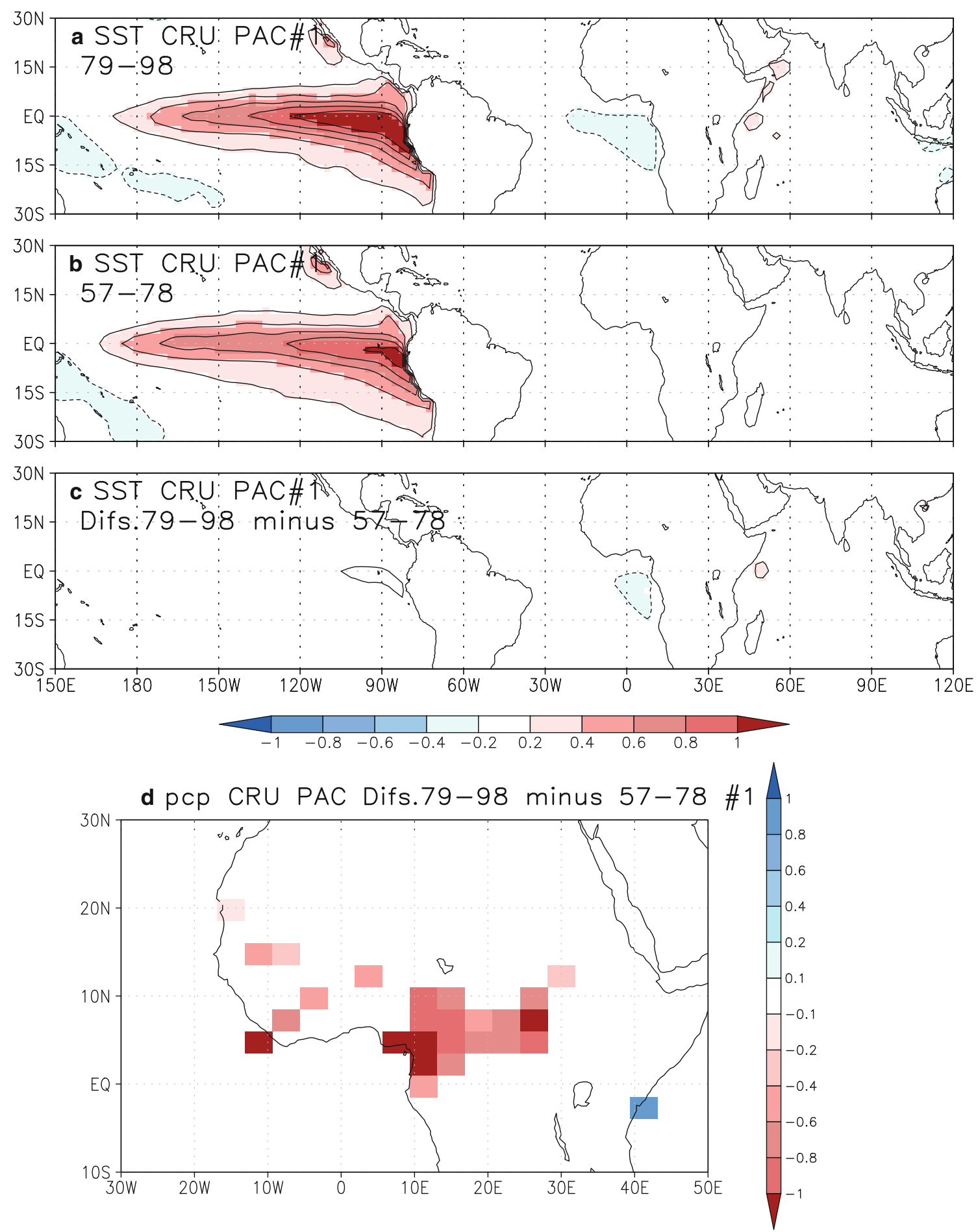

Fig. 8 Same as Fig. 5 but for the first co-variability mode between observed July to September (JJAS) standardized precipitation over West Africa and Pacific SSTs

rainfall appeared anticorrelated with a dipolar structure that reflects a shift in the position of the Inter-Tropical Convergence Zone, whilst for the years in which the Guinea Gulf is related to ENSO, the correlation between Sahel and Guinea decreased and there is a modulation of the rainfall along the seasonal cycle. As was shown in previous sections, models are more sensitive to SST anomalies in the Atlantic Ocean than in the Pacific, due to the more direct impact that the former have in the Atmospheric circulation over West Africa. Thus, one would expect the failure in the 
Fig. 9 Same as Fig. 6 but for the first co-variability mode between simulated July to September $(J J A S)$ standardized precipitation over West Africa and Pacific SSTs
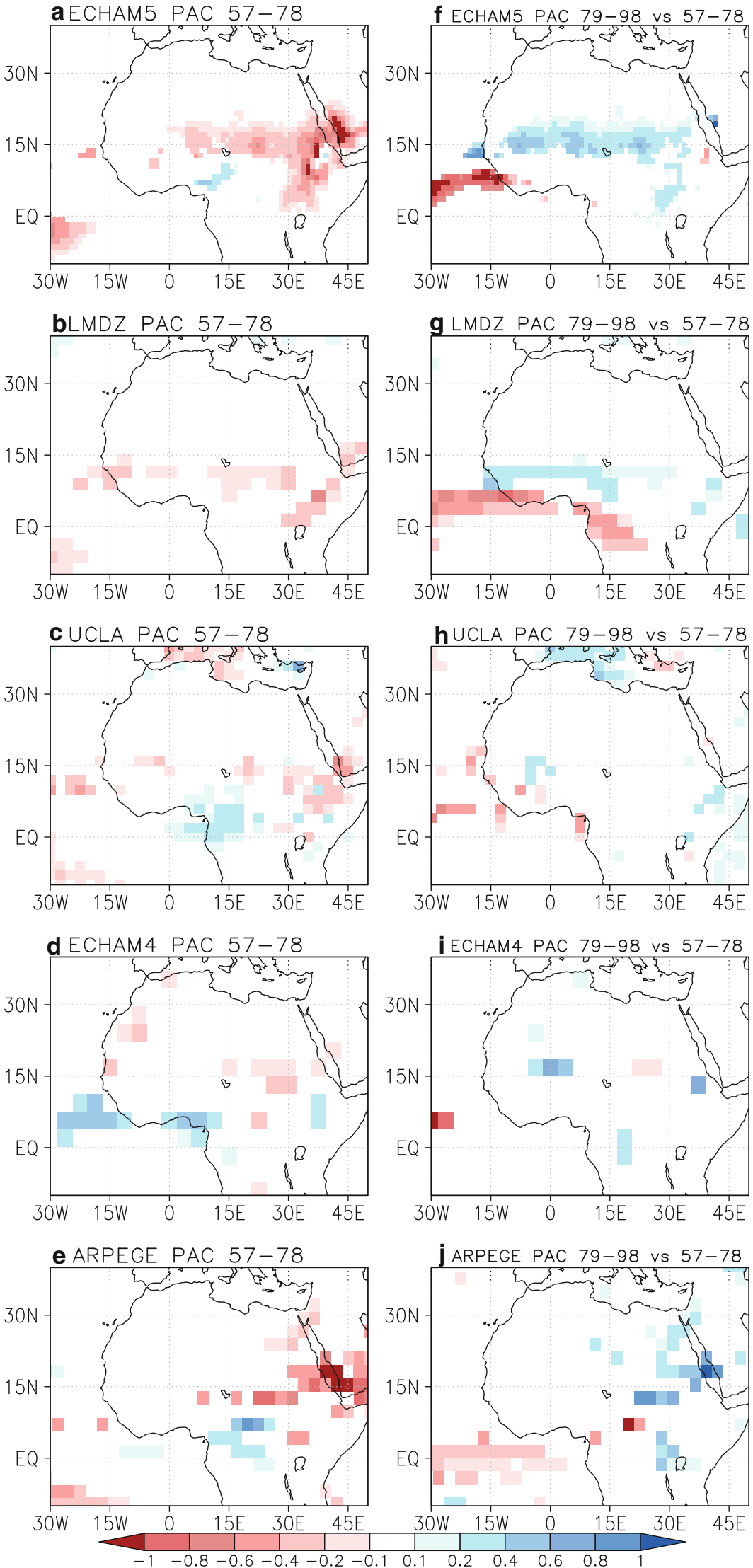
representation of the non-dipolar precipitation response observed in West Africa during the second period, and the presence of dipolar response more coherent with a response to the Atlantic anomalous SSTs.

\subsubsection{Mediterranean SST-West African precipitation}

The period after the 1970s has also striking significant differences regarding the West Africa-Mediterranean teleconnections. On the one hand, Polo et al. (2008) have shown how the Mediterranean mode appears, after the 1970s, as an SST pattern that is not related to the variability in the tropical SSTs, so it can be considered isolated from the tropical influence. On the other hand, the response to this Mediterranean mode is analysed in Fontaine et al. (2010), who find that the warmer eastern Mediterranean increases the specific humidity in the low-levels and the northeasterly moisture flux, strengthening the convergence in low levels and thus, the monsoon.

Figure 10 summarizes the results for the first mode of co-variability between observed and simulated West African precipitation and Mediterranean SSTs for the 79-98 period. It shows the mode for CMAP and CRU observational data sets, as well as for the LMDZ and UCLA models. The rest of the models, including the multimodel ensemble, show no robust modes. The squared covariance fraction explained by this first mode are 33, 31, 32 and $30 \%$, respectively. No result is shown in relation to the 1957-1978 period because first of all, the obtained mode is not robust, and second, the mode appears as a fingerprint of a more global pattern (not shown).

Regarding the observations, CRU and CMAP data sets show an increase in precipitation over the Sahel related to a warmer Mediterranean Sea, in agreement with other studies (Rowell 2003; Jung et al. 2006; Fontaine et al. 2010; Polo et al. 2008) (Fig. 10). There is also a decrease in rainfall over the oceanic eastern Guinea Gulf (only in CMAP). The LMDZ and UCLA models capture this weakening and they also show an increased rainfall over Sahel (Fig. 10).

The 1979-1998 SST pattern shows no loadings over the tropical oceans, except for a weak cooling in the central equatorial Pacific, and over the eastern equatorial Atlantic (not shown). This latter pattern could be related to the decrease in precipitation shown by CMAP and the models over the Guinea Coast.

\section{Summary and conclusions}

A fundamental goal of climate research is the development of models simulating a realistic present climate, in order to increase its reliability in future projections. In this way, the Sahelian rainfall interannual and decadal variability is a good subject to evaluate climate models. The ocean forcing has been highlighted to be the main driver of the long drought period that started over Sahel in the 1970s (Giannini et al. 2003; Lu and Delworth 2005; Cook 2008; Caminade and Terray 2010; Mohino et al. 2010). For this reason, state-of-the-art climate models are requested to reproduce the main features of the observed Sahelian rainfall time series when forced by observed SSTs.

The focus of the study is twofold: to explore the change in the interannual variability of West African rainfall after the climate shift of the 1970s and to evaluate the reliability of different simulations (done with different models) and the multimodel approach in reproducing this variability. We have focused here on the relationship between West African rainfall and the oceanic forcing represented by the SST applying a multivariate analysis to the observed data and to different model outputs.

Regarding the first goal, the most remarkable result of this study is the description of the change in the properties of the interannual variability of West African precipitation in relation to the oceanic forcing. The dipolar features in the rainfall pattern of the observed Atlantic SST-West African precipitation co-variability shown for the 1957-1978 period disappear when considering the 1979-1998 one. Our results suggest that this behaviour is related to the concomitant presence of opposite signed SST anomalies in the tropical Pacific described in Rodriguez-Fonseca et al. (2009). In turn, in the second period, the Pacific mode shows higher correlations over the whole West Africa, and not only over the Sahel. It was shown that this change could be related to the concomitant presence of opposite signed SST anomalies in the eastern equatorial Atlantic.

In relation to the models, the multimodel ensemble mean sums up well the common capacity of the different models: it reasonably reproduces the mean climatology of West African summer rainfall and the annual cycle of the monsoon, though its onset occurs 1 month earlier (end of May) than in the observations (end of June). Rainfall associated with the preonset is overestimated in half of the simulations. The models examined show a lot of coherent responses but also differences in their simulation of interannual variability of West African rainfall. One simulation is available for the ARPEGE and ECHAM4 model while for the others (LMDZ, UCLA and ECHAM5) we have been able to analyse the averaged responses based on 4-6 simulations, reducing the internal atmospheric variability and enhancing the SST-forced signal. The interannual variability of Guinea Coast precipitation, related to the second observed EOF, is captured by most models, while Sahelian rainfall variability, related to the first observed EOF, is poorly provided. This is consistent with the results of Paeth and Hense (2004) and Philippon et al. (2010) who concluded that the Guinean domain, close to the Atlantic 


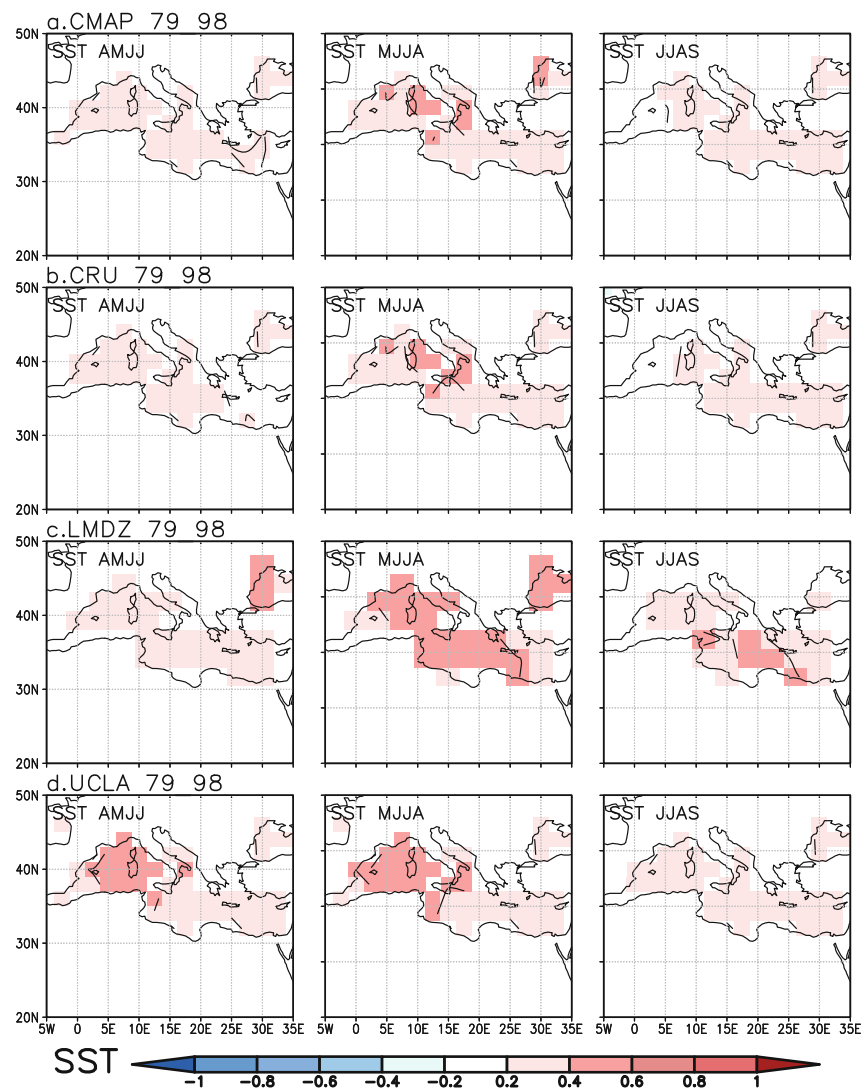

Fig. 10 First co-variability mode (calculated using EMCA methodology) between observed and simulated July to September (JJAS) standardized precipitation over West Africa and Mediterranean SSTs in the 1979-1998 period for: a CMAP, b CRU, c LMDZ and d ULCA. The homogeneous SST maps (left) are shown for the April to July (AMJJ) (first column), May to August (MJJA) (second column) and July to September (JJAS) (third column) seasons. Heterogeneous JJAS precipitation maps are shown in the fourth column. Units are $\mathrm{mm} /$ day per standard deviation of SST expansion

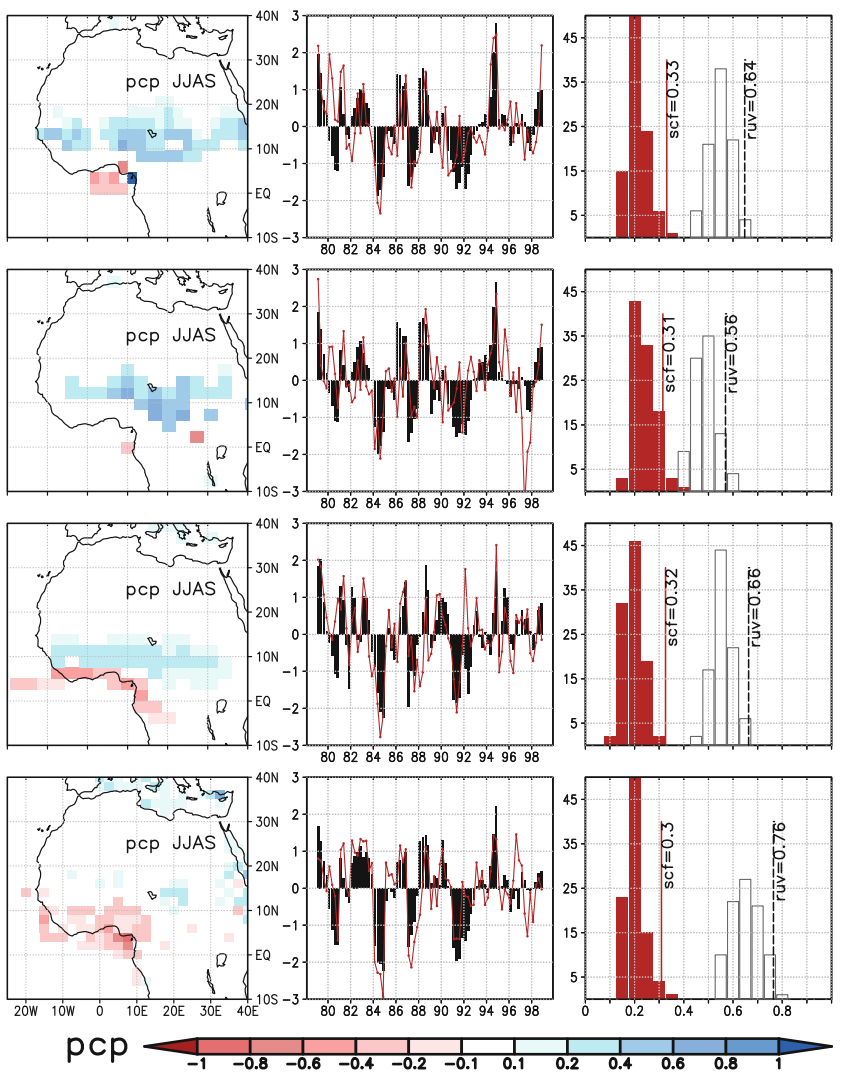

coefficient, and K per standard deviation of SST expansion coefficient, respectively. Only 95\% significant anomalies are shown (according to a t-test). The SST (rainfall) expansion coefficients are shown in black ( $r e d$ ) in the fifth column. Probability density functions calculated by Monte Carlo technique are shown in the sixth column for the squared co-variance fraction (scf) (red solid bars) and correlation coefficient (ruv) (dark grey open bars). The original squared covariance fraction and correlation coefficients are indicated as red and dark grey lines, respectively ocean, is more strongly controlled by SSTs than the Sahelian one.

Regarding the analysis of maximum covariance between the anomalous SST and West African precipitation variability, a strong positive link appears between the summer anomalous rainfall over the Guinean region and the Equatorial Atlantic SST mode evolution from spring to summer for the observations, multimodel ensemble and all the models. Concerning the Pacific, the coupled anomalous West African rainfall-Pacific SST mode always depict an El Niño-like pattern in the Pacific. However, the simulated related rainfall pattern does not always agree with the observed one. Finally, not all the models are able to show a robust Mediterranean SST-West African precipitation mode; only the LMDZ and UCLA models capture the observed connection between warmer Mediterranean SST and increased rainfall over the Sahel after the 1970s.
In spite of an agreement over the oceanic part of West Africa, changes in the Atlantic interannual SST-precipitation co-variability mode show important differences among models over land. This could be due to the poorer performance of models when simulating non linear aspects of the teleconnections with the Pacific, including atmosphereland surface feedbacks. Conversely, for the Pacific, the changes in the mode are more consistent among models, because they are related to the Atlantic SST anomalies, which have a more direct influence on West Africa.

Acknowledgments We would like to thank the anonymous reviewers for their comments and suggestions that helped improved the manuscript. This project has been funded by the EU-AMMA project. Based on French initiative, AMMA was built by an international scientific group and is currently funded by a large number of agencies, especially from France, UK, US and Africa. It has been the beneficiary of a major financial contribution from the European Community's Sixth Framework Research Programme. Detailed 
information on scientific coordination and funding is available on the AMMA International website http://www.amma-international.org. EM would like to thank the support from the programme POSDEXTMEC of the Spanish Ministry for Science and Innovation. JB would also want to thank the support from the COMPAS project funded by the research council of Norway. This study was supported also by the Spanish projects: MEC CGL2006-04471, MEC CGL2009-10285 and MMA MOVAC:200800050084028. GR58/08 program (supported by BSCH and UCM) has also partially financed this work through the Research Group "Micrometeorology and Climate Variability" (no. 910437).

\section{References}

Bader J, Latif M (2003) The impact of decadal scale Indian Ocean SST anomalies on Sahelian rainfall and the North Atlantic oscillation. Geophys Res Lett 30:2169. doi:10.1029/2003GL0 18426

Bader J, Latif M (2010) The 1983 drought in the West Sahel: a case study. Clim Dyn. doi:10.1007/s00382-009-0700-y

Bretherton CS, Smith C, Wallace JM (1992) An intercomparison of methods for finding coupled patterns in climate data. J Clim 5:541-560

Camberlin P, Janicot S, Poccard I (2001) Seasonality and atmospheric dynamics of the teleconnection between African rainfall and tropical sea-surface temperature: Atlantic vs. ENSO. Int J Climatol 21:973-1005. doi:10.1002/joc.673

Caminade C, Terray L (2010) Twentieth century Sahel rainfall variability as simulated by the ARPEGE AGCM, and future changes. Clim Dyn 35:75-94

Cane MA, Clement AC, Kaplan A, Kushnir Y, Pozdnyakov D, Seager R, Zebiak SE, Murtugudde R (1997) Twentieth-century sea surface temperature trends. Science 275:957-960. doi:10.1126/ science.275.5302.957

Cook K (2008) The mysteries of Sahel droughts. Nature Geosci 1:647-648

Déqué M, Dreveton C, Braun A, Cariolle D (1994) The ARPEGE/IFS atmosphere model: a contribution to the French community climate modeling. Clim Dyn 10:249-266

Fiorino (2000) Web document: http://www-pcmdi.llnl.gov/projects/ amip/AMIP2EXPDSN/BCS_OBS/amip2_bcs.htm

Folland CK, Palmer TN, Parker DE (1986) Sahel rainfall and worldwide sea temperatures, 1901-85. Nature 320:602-607. doi: $10.1038 / 320602 \mathrm{a} 0$

Folland CK, Owen J, Ward MN, Colman A (1991) Prediction of seasonal rainfall in the Sahel region using empirical and dynamical methods. J Forecast 10(1-2):21-56

Fontaine B, Janicot S (1996) Near-global sea surface temperature variability associated with West African rainfall anomaly types. J Clim 9:2935-2940

Fontaine B, Janicot S, Moron V (1995) Rainfall anomaly patterns and wind field signals over West Africa in August (1958-1989). J Climate 8:1503-1510

Fontaine B, Garcia-Serrano J, Roucou P, Rodriguez-Fonseca B, Losada T, Chauvin F, Gervois S, Sijikumar S, Ruti P, Janicot S (2010) Impacts of warm and cold situations in the Mediterranean basins on the West African monsoon: observed connection patterns (1979-2006) and climate simulations. Clim Dyn 35:95-114. doi:10.1007/s00382-009-0599-3

Frankignoul C, Kestenare E (2005) Observed Atlantic SST anomaly impact on the NAO: an update. J Clim 18:4089-4094

Giannini A, Saravannan R, Chang P (2003) Oceanic forcing of Sahel rainfall on interannual to interdecadal time scales. Science 302:1027-1030
Giannini A, Saravannan R, Chang P (2005) Dynamics of the boreal summer African monsoon in the NSIPP1 atmospheric model. Clim Dyn 25:517-535. doi:10.1007/s00382-005-0056

Graham NE (1994) Decadal-scale climate variability in the tropical and North Pacific during the $1970 \mathrm{~s}$ and $1980 \mathrm{~s}$ : observations and model results. Clim Dyn 10:135-162

Haarsma RJ, Selten FM, Weber SL, Kliphuis M (2005) Sahel rainfall variability and response to greenhouse warming. Geophys Res Lett 32:L17702. doi:10.1029/2005GL023232

Hoerling M, Hurrell JW, Eischeid J, Phillips AS (2006) Detection and attribution of twentieth-century Northern and Southern African rainfall change. J Clim 19:3989-4008

Hourdin F, Musat I, Bony S, Braconnot P, Codron F, Dufresne JL, Fairhead L, Filiberti MA, Friedlingstein P, Grandpeix JY, Krinner G, LeVan P, Li ZX, Lott F (2006) The LMDZ4 general circulation model: climate performance and sensitivity to parametrized physics with emphasis on tropical convection. Clim Dyn 27:787-813

Hulme M (1992) A 1951-80 global land precipitation climatology for the evaluation of general circulation models. Clim Dyn 7:57-72

Janicot S (1992a) Spatio-temporal variability of West African rainfall. Part I: regionalization and typings. J Clim 5:489-497

Janicot S (1992b) Spatio-temporal variability of West African rainfall. Part II: associated surface and airmass characteristics. J Clim 5:499-511

Janicot S, Moron V, Fontaine B (1996) ENSO dynamics and Sahel droughts. Geophys Res Lett 23(5):515-518

Janicot S, Harzallah A, Fontaine B, Moron V (1998) West African monsoon dynamics and eastern equatorial Atlantic and Pacific SST anomalies (1970-1988). J Clim 11:1874-1882

Janicot S, Trzaska S, Poccard I (2001) Summer Sahel-ENSO teleconnection and decadal time scale SST variations. Clim Dyn 18:303-320

Janowiak JE (1988) An investigation of interannual rainfall variability in Africa. J Clim 1:240-255

Joly M, Voldoire A (2010) Role of the Gulf of Guinea in the interannual variability of the West African Monsoon: what do we learn from CMIP3 coupled simulations? Int J Clim 12:1843-1856. doi:10.1003/joc.2026

Joly M, Voldoire A, Douville H, Terray P, Royer JF (2007) African monsoon teleconnections with tropical SSTs: validation and evolution in a set of IPCC4 simulations. Clim Dyn 29:1-20. doi: 10.1007/s00382-006-0215-8

Jung T, Ferranti L, Tompkins AM (2006) Response to the summer of 2003 Mediterranean SST anomalies over Europe and Africa. J Clim 19:5439-5454

Kaiser HF (1958) The varimax criterion for analytic rotation in factor analysis. Psychometrika 23:187-200

Kamga AF, Jenkins GS, Gaye AT, Garba A, Sarr A, Adedoyin A (2005) Evaluating the National Center for Atmospheric Research climate system model over West Africa: present-day and the 21st century A1 scenario. J Geophys Res 110:D03106. doi:10.1029/ 2004JD004689

Krishnamurti TN, Kishtawal CM, Zhang Z, LaRow T, Bachiochi D, Williford E, Gadgil S, Surendran S (2000a) Multimodel ensemble forecasts for weather and seasonal climate. J Clim 13:4196-4216

Krishnamurti TN, Kishtawal CM, Shin DW, Williford CE (2000b) Improving tropical precipitation forecasts from a multianalysis superensemble. J Clim 13:4217-4227

Kucharski F, Bracco A, Yoo JH, Molteni F (2007) Low-frequency variability of the Indian Monsoon-ENSO relationship and the Tropical Atlantic: the "Weakening" of the $1980 \mathrm{~s}$ and $1990 \mathrm{~s}$. J Clim 20:4255-4266

Kucharski F, Bracco A, Yoo JH, Molteni F (2008) Atlantic forced component of the Indian monsoon interannual variability. Geophys Res Lett 35:L04706. doi:10.1029/2007GL033037 
Kumar KK, Rajagopalan B, Cane MA (1999) On the weakening relationship between the Indian Monsoon and ENSO. Nature 284:2156-2159

Losada T, Rodriguez-Fonseca B, Janicot S, Gervois S, Chauvin F, Ruti P (2010) A multi-model approach to the Atlantic Equatorial mode: impact on the West African monsoon. Clim Dyn 35:29-43. doi:10.1007/s00382-009-0625-5

Lu J, Delworth TL (2005) Oceanic forcing of the late 20th century Sahel drought. Geophys Res Lett 32:L22706. doi:10.1029/ 2005GL023316

Miller AJ, Cayan DR, Barnett TP, Graham NE, Oberhuber JM (1994) The 1979-77 climate shift of the Pacific Ocean. Oceanography $7: 21-26$

Mohino E, Janicot S, Bader J (2010) Sahel rainfall and decadal to multi-decadal sea surface temperature variability. Climate Dyn. doi:10.1007/s00382-010-0867-2

Mohino E, Rodriguez-Fonseca B, Mechoso CR, Gervois S, Ruti P, Chauvin F (2011) Impacts of the tropical Pacific/Indian Oceans on the seasonal cycle of the West African Monsoon. J Clim. doi: 10.1175/2011JCLI3988.1

Moron V, Philippon N, Fontaine B (2003) Skill of Sahel rainfall variability in four atmospheric GCMs forced by prescribed SST. Geophys Res Lett 30:2221. doi:10.1029/2003GL018006

Moron V, Philippon N, Fontaine B (2004) Simulation of West African monsoon circulation in four atmospheric general circulation models forced by prescribed sea surface temperature. J Geophys Res 209. doi:10.1029/2004JD004760

Motha RP, Leduc SK, Steyaert LT, Sakamoto CM, Strommen ND (1980) Precipitation patterns in West Africa. Mon Wea Rev 108:1567-1578

Paeth H, Hense A (2004) SST versus climate change signals in West African rainfall: 20th century variations and future projections. Clim Change 65:179-208

Palmer TN (1986) Influence of the Atlantic, Pacific, and Indian Oceans on Sahel rainfall. Nature 322:251-253

Philippon N, Doblas-Reyes FJ, Ruti PM (2010) Skill, reproducibility and potential predictability of the West African monsoon in coupled GCMs. Clim Dyn 35:53-74

Polo I, Rodriguez-Fonseca B, Losada T, Garcia Serrano J (2008) Tropical Atlantic Climate variability and Atlantic extratropical teleconnections. Part I: air sea interactions. J Clim 21:6457-6475

Rayner NA, Horton EB, Parker DE, Folland CK, Hackett RB (1996) Version 2.2 of the global sea-ice and sea surface temperature data set, 1903-1994. Climate research technical note no. 74 . Hadley Centre for Climate Prediction and Research. Meteorological Office, UK

Rayner NA, Parker DE, Horton EB, Folland CK, Alexander LV, Rowell DP, Kent REC, Kaplan A (2003) Global analyses of sea surface temperature, sea ice, and night marine air temperature since the late nineteenth century. J Geophys Res 108:4407. doi: 10.1029/2002JD002670

Reynolds RW, Smith TM (1994) Improved global sea surface temperature analyses using optimum interpolation. J Clim 7:929-948

Reynolds RW, Rayner NA, Smith TM, Stokes DC, Wang W (2002) An improved in situ satellite SST analysis for climate. J Clim 15:1609-1625

Richter I, Mechoso CR, Robertson AW (2008) What determines the position and intensity of the South Atlantic anticyclone in austral winter?-An AGCM study. J Clim 21:214-229

Robertson AW, Ferrara JD, Mechoso CR (2003) Simulations of the atmospheric response to south Atlantic sea surface temperature anomalies. J Clim 16:2540-2551

Rodriguez-Fonseca B, Polo I, Garcia-Serrano J, Losada T, Mohino E, Mechoso CR, Kucharski F (2009) Are Atlantic Niños enhancing
Pacific ENSO events in recent decades? Geophys Res Lett 36:L20705. doi:10.1029/2009GL040048

Rodriguez-Fonseca B, Janicot S, Mohino E, Losada T, Bader J, Caminade C, Chauvin F, Fontaine B, Garcia-Serrano J, Gervois S, Joly M, Polo I, Ruti P, Roucou P, Voldoire A (2010) Interannual and decadal SST-forced responses of the West African monsoon. Atmos Sci Let. doi:10.1002/asl.308

Roeckner E, Bäuml G, Bonaventura L, Brokopf R, Esch M, Giorgetta M, Hagemann S, Kirchner I, Kornblueh L, Manzini E, Rhodin A, Schlese U, Schulzweida U, Tompkins A (2003) The atmosphere general circulation model ECHAM5, part I: model description. Max-Planck Institute for Meteorology

Rowell DP (2001) Teleconnections between the tropical Pacific and the Sahel. Q J R Meteorol Soc 127:1683-1706

Rowell DP (2003) The impact of the Mediterranean SSTs on the Sahelian rainfall season. J Clim 16:849-862

Rowell DP, Folland CK, Maskell K, Owen JA, Ward NM (1992) Modelling the influence of global sea surface temperatures on the variability and predictability of seasonal Sahel rainfall. Geophys Res Lett 19:905-908

Rowell DP, Folland CK, Maskell K, Ward NM (1995) Variability of summer rainfall over tropical North Africa (1906-92): observations and modelling. Q J R Meteorol Soc 121:669-704

Ruti PM, Di Rocco D, Gualdi S (2006) Vertical resolution impact on the simulation of the Tropical Climate'. Theor Appl Climatol 85:61-80. doi:10.1007/s00704-005-0174-8

Smith TM, Reynolds W (2004) Improved extended reconstruction of SST (1854-1997). J Clim 17:2466-2477

Sultan B, Janicot S (2000) Abrupt shift of the ITCZ over West Africa and intra-seasonal variability. Geophys Res Lett 27:3353-3356

Sultan B, Janicot S (2003) The West African monsoon dynamics. Part II: the "preonset" and "onset" of the summer monsoon. J Clim 16:3389-3406

Tennant W (2003) An assessment of intraseasonal variability from 13-Yr GCM simulations. Mon Wea Rev 131:1975-1991

Tippett MK (2006) Filtering of GCM simulated Sahel precipitation. Geophys Res Lett 33:L01804. doi:10.1029/2005GL024923

Trenberth KE, Caron JM, Stepaniak DP, Worley S (2002) Evolution of El Niño-Southern Oscillation and global atmospheric surface temperatures. J Geophys Res 107. doi:10.1029/2000JD000298

Trenberth KE, Jones PD, Ambenje P, Bojariu R, Easterling D, Klein Tank A, Parker D, Rahimzadeh F, Renwick JA, Rusticucci M, Soden B, Zhai P (2007) Observations: surface and atmospheric climate change. In: Solomon S, Qin D, Manning M, Chen Z, Marquis M, Averyt KB, Tignor M, Miller HL (eds.) Climate change 2007: the physical science basis. Contribution of working group I to the fourth assessment report of the intergovernmental panel on climate change. Cambridge University Press, Cambridge

Vizy EK, Cook KH (2001) Mechanisms by which Gulf of Guinea and Eastern North Atlantic Sea surface temperature anomalies can influence African rainfall. J Clim 14:795-821

Vizy EK, Cook KH (2002) Development and application of a mesoscale climate model for the tropics: influence of sea surface temperature anomalies on the West African monsoon. J Geophys Res 107(D3). doi:10.1029/2001JD000686

Von Storch H, Navarra A (1995) Analysis of climate variability: applications of statistical techniques. Springer, Berlin

Ward MN (1998) Diagnosis and short-lead time prediction of summer rainfall in tropical North Africa at interannual and multidecadal timescales. J Clim 11:3167-3191

Xie P, Arkin PA (1997) Global precipitation: a 17-year monthly analysis based on gauge observations, satellite estimates, and numerical model outputs. Bull Amer Meteor Soc 78:2539-2558

Zebiak SE (1993) Air-sea interaction in the equatorial Atlantic region. J Clim 6:1567-1586 